\title{
Adaptive Congestion Prediction in Vehicular Ad-hoc Networks (VANET) using Type-2 Fuzzy Model to Establish Reliable Routes
}

Lokesh Manohar Giripunje ( $\sim$ lokeshgiripunje@gmail.com )

VIT Bhopal University https://orcid.org/0000-0002-0505-9795

Abhay Vidyarthi

VIT Bhopal University

Shishir Kumar Shandilya

VIT University Bhopal

\section{Research Article}

Keywords: Artificial intelligence, carbon dioxide, congestion, fuzzy logic, VANET, quality of service

Posted Date: April 27th, 2021

DOI: https://doi.org/10.21203/rs.3.rs-458059/v1

License: (c) (i) This work is licensed under a Creative Commons Attribution 4.0 International License.

Read Full License 


\title{
Adaptive Congestion Prediction in Vehicular Ad-hoc Networks (VANET) using Type-2 Fuzzy Model to Establish Reliable Routes
}

\author{
Lokesh M. Giripunje, Abhay Vidyarthi and Shishir Kumar Shandilya \\ VIT Bhopal University, Bhopal,India \\ lokeshgiripunje@gmail.com
}

\begin{abstract}
In urban areas, a significant increase in vehicles day-by-day leads to challenges like accidents and pollutions such as air and noise. The emission of Carbon dioxide (CO2) from vehicles leads to air pollution. The major cause of increased emission is traffic conditions in urban areas. Thus, Quality of Service (QoS) becomes a very challenging research problem by considering eco-friendly and reliable transportations. The appropriate congestion or traffic situation management techniques reduce the possibilities of accidents and pollutions. The congestion control methods should take into account the properties such as fairness, decentralization, network characteristics, and application demands in VANET. The current methods failed to address all such properties and trade-offs for VANET communications. This paper proposed Adaptive Congestion Aware Routing Protocol (ACARP) for VANET using the dynamical artificial intelligence (AI) technique. In ACARP, the adaptive congestion detection algorithm is designed using the type- 2 fuzzy logic AI technique. The fuzzy model builds to detect the congestion around each vehicle using three fuzzy-inputs such as bandwidth occupation, link quality, and moving speed. Using three parameters, the fuzzy rules are designed in the first phase. In the second phase, the inferences model introduced where the fuzzy decision has been made. In the last phase, defuzzifuzification is applied and the congestion probability estimated in the range of $0-1$ for each vehicle. Then the status of congestion detection updated using the pre-defined threshold value for each vehicle. The status of congestion and its probability values have been utilized to establish safe and reliable routes for data transmission. It saves significant communication overhead and hence $\mathrm{CO} 2$ emissions in the network. The simulation results prove that the planned protocol improved the QoS presentation and significant $\mathrm{CO} 2$ emission compared to underlying fuzzy-based methods.
\end{abstract}

Keywords: Artificial intelligence, carbon dioxide, congestion, fuzzy logic, VANET, quality of service.

\section{Declarations:}

Funding: Not Applicable

Conflicts of interest/Competing interests: The author(s) declare(s) that there is no conflict of interest'.

Availability of data and material: Yes

Code availability: Custom code

\section{Introduction}

Due to the appearance of the Internet of Things (IoT) [1] [2] and Industry 4.0 standards for various smart city applications worldwide, the Intelligent Transportation System (ITS) gained significant attention from the researchers. Vehicular Ad Hoc Networks (VANETs) is a key component of smart ITS and plays 
a significant role in IoT [3-6]. In general, VANET assists vehicle drivers to communicate (through enabling Vehicle-to-Vehicle (V2V) and Vehicle-toInfrastructure (V2I) communications) to avoid many critical driving situations [7]. VANETs underpins an assortment of security applications, for example, coemployable traffic observing, control of traffic streams, daze crossing, avoidance of impacts, close by data services, and continuous re-route courses calculation. VANETs comprise of two substances: passages, called Road Side Units (RSUs), and vehicles called On-Board Unit (OBUs). RSUs are fixed and can go about as an appropriation point for vehicle networks. The major entities of the VANET are vehicles, RUSs, and OBUs, where they transmit information by using vehicle-tovehicle communication (V2V), infrastructure-to-infrastructure (I2I), and vehicle-toinfrastructure (V2I) communications [8]. These communications have been supported by dedicated short-range communication (DSRC). This vehicular communication system is accessed by the standard IEEE $802.11 \mathrm{p}$ that supports wireless access in vehicular environments (WAVE). The IEEE 802.11p defines the link layer that supports internet protocol and the WAVE short message protocol (WSMP) [9] [10]. The WAVE standard limits basic circumstances, for example, counteraction or ID of the event of mishaps. The intelligent transport systems (ITS) utilization the WAVE convention to communicate data, for example, climate conditions, streets support, and street traffic conditions.

VANETs deployment having several challenges that needs to be conquering by appropriate routing methodology. The challenges are congestion in the network, severe mobility, high computational efforts, and data loss [11]. VANETs give Web network to vehicles while moving, so travellers can download music, send messages, book eateries, or potentially mess around. Because of the vehicle's fast movement, vehicular networks are described by quick geography changes that lead to serious congestions in the network [12]. Furthermore, thus it makes the planning of effective steering convention for the vehicular climate troublesome. Planning versatile congestion mindful directing conventions to such quickly changing network geographies is exceptionally basic to numerous vehicular security applications such as neglecting to course impact evasion messages to their expected vehicles can deliver these messages to be pointless. The directing assumes a significant function in the wellbeing uses of VANET for moving the information between end-clients. It noticed that designing routing protocol for VANET is challenging due to (1) Dynamic topology changes due to high mobility; (2) Frequent link disconnections due to the mobility speed; (3) Flexibility to select alternate routes for data transmission; (4) Capability to tolerate faults such as link breakages and nodes' positions; and (5) automatic mitigation of RSU failures without compromising the QoS of VANET communication [13]. The first reason for which VANETs have been organized comprises the arrangement of constant and security applications for drivers and travellers: they can communicate continuous alarms to drivers about dangers on their arranged excursion and their prompt environmental factors. Following these circumstances, it tends to be expressed that especially during the most recent decade, VANETs are promising in a few valuable drivers and traveller situated services that incorporate, for instance, on-request Web associations and interactive media services. The adaptability and interoperability are two significant issues that should be fulfilled, by and large, conveying satisfactory steering 
conventions and components ready to interoperate with various vehicles and distinctive remote innovations. It is realized that $\mathrm{V} 2 \mathrm{~V}$ correspondence permits the advancement of new applications that incline toward dependable lower-layer conventions for example steering conventions.

For road safety applications, several factors are included like congestion that leads to pollutions (noise and air), high travelling time, road accidents, and degraded QoS performance of VANET [14]. These problems become severe for urban areas due to the high volume of vehicles travelling at day time. In such situations, drivers would like to avoid congested roads during their journeys and save fuel and travelling time [15]. The congestion plays a significant factor in VANET QoS performance and environmental impacts (CO2 emission), especially in VANET safety applications [16-20]. The congestion control can be achieved by the routing functions, thus the appropriate congestion or overload situation management techniques reduce the possibilities of accidents and pollutions in urban areas. In this paper, we formulate the problem of $\mathrm{CO} 2$ emission control employing congestion control and safer routes establishment in VANETs. The Adaptive Congestion Aware Routing Protocol (ACARP) planned in this paper to dynamically perform the prediction of congestion in the network and establish the safer and reliable routes in VANET so that it leads to improved network QoS and reduced pollutions. The QoS boundaries of VANETs are normal throughput, Bundle Conveyance Proportion (PDR), correspondence delay, and directing overhead. For congestion prediction, we designed the artificial intelligence (AI) technique called Type-2 Fuzzy logic system using the three parameters of each vehicle bandwidth occupation, link quality, and mobility. The congestion status and probabilities are computed periodically for each vehicle and updated in the routing table. Segment 2 presents a short survey of related works and examination inspiration. Segment 3 presents the proposed philosophy. Area 4 presents the re-enactment results and investigation. Segment 5 presents the end and future bearings of this work.

\section{Related Works}

Due to the emergence of IoT-assisted smart city applications, several researchers proposed solutions for VANET routing by considering the reliability and safety challenges. For this work, various congestion-aware and reliable routing methods studied are overlapping to the proposed protocol of this paper. The congestion detection in VANET is asignificant research problem, for that purpose, various techniques used like trust-computations, fuzzy logic, and other AI based approaches. This section first presents the related works on congestion detection and control in VANET and then research motivation and contributions.

\section{A. Congestion Detection and Control}

As we formulate the problem of $\mathrm{CO} 2$ emission reduction as adaptive congestion detection and control in VANET, recent methods introduced in [21-35] reviewed. The DCAR (data congestion-aware routing protocol) was proposed in [21] as an intersection-based low-layer protocol for VANET. They used the road segments estimation-based vehicular traffic and data traffic parameters to contrast the paths, however, the lack of adaptive nature of this protocol leads to reliability-related challenges. The congestion-aware routing protocol was proposed for urban regions 
in [22] to enhance the presentation of the existing protocol. The congestion is estimated using two parameters available queue size and geographical distance among current node and particular destination vehicle. These values are computed for each vehicle at the time of the route discovery phase to transmit data from source to destination, and hence it takes a longer time to discover the route and hence leads to higher communication delay and data loss. Another congestion-aware routing method is designed for urban areas called GTLQR (greedy traffic light \& queueaware routing) in [23]. In GTLQR, they used the parameters such as channel quality, queuing delay, street connectivity, and relative distance to reduce the congestion and hence data loss in VANET. They focused on balancing only traffic load on vehicles in-network; however, it is not enough to establish safer and reliable paths in highly dynamic networks. In [24], the author presented a good study of various congestion/traffic aware routing methods along with challenges and future directions. They emphasized on challenges of awareness of network conditions and traffic in VANET routing protocols. Various traffic-aware protocols are investigated along with their benefits and limitations by disclosing the phases like routing, forwarding, recovery, etc. Another reliable route establishment protocol proposed recently in [25] called RPSPF (reliable path selection \& packet forwarding) protocol. They computed the shortest distance (according to intersections) and connectivity parameters to build the optimal route to transmit data from source vehicle to destination vehicle. After that, a reliable data forwarding technique was designed among the intersections to prevent data loss. However, as mentioned above, this approach also adds higher computation burden and delay in case of severe dynamics. The FL-CFT (fuzzy logic-based cooperative file transfer) protocol was proposed in [26] for VANET. They designed protocol mainly for the bi-directional highway mobility scenario to address the challenges of the file transfer. This work is not related to our problems; however, it demonstrates how fuzzy logic is applied to establish the routing in complicated network conditions.

The clustering algorithm was introduced in [27] for congestion control in VANETs. They used the fuzzy C-means algorithm to cluster the messages received at the RSU unit to prevent the problems of collisions and hence congestions in the network. The messages were clustered into various strategies and minimized the number of packets transmission. However, it is not a scalable solution by considering the higher density and mobility of vehicles in urban areas. Another good study over the various congestion-aware methods presented in [28] similar to [24], however, with more recent works. They discovered the performance metrics and parameters that can be utilized for the evaluation of congestion-aware protocols. They disclosed the challenges of designing $\mathrm{V} 2 \mathrm{~V}$ communication protocols and future directions at the end. The modified AODV protocol was proposed in [29] to mitigate the challenges of reliable and safer route discovery for data transmission. They used the TOPSIS and fuzzy techniques to improve AODV performance by discovering the most reliable route to prevent data loss. However, the lack of adaptive congestion detection may lead to performance challenges under critical network conditions. Recently, the QoS evaluation technique proposed for VANET in [30] using the fuzzy logic algorithm. The holistic model was proposed to overcome the challenges of estimating VANET QoS performances by considering the various applications and services. However, as this approach only focused on QoS performance evaluation 
using fuzzy logic, challenges of congestion control and safer route establishment cannot be addressed. Another route discovery protocol was introduced in [31] to achieve the congestion aware routing in VANET. They formulated the congestion probability by considering the non-equipped and equipped vehicles besides driver distraction parameters. However, the approach is not lightweight as it involves the computation of driver distraction factors as well to estimate the congestion indexing and hence may lead to longer latency and packet loss.

The relevant study reported in [32] where the routing mechanism proposed to reduce the accidents, congestion, and pollution. They designed protocol with adaptive traffic signals as well as emergency vehicle management in VANETs using the fuzzy logic approach. They designed a completely adaptive and dynamic congestion control strategy for VANETs; however, the set of fuzzy rules is limited that may lead to unreliable network solutions for scalable and highly dynamic networks. The first standard work introduced in [33] focused on the reduction in $\mathrm{CO} 2$ emissions by employing congestion levels reduction. They worked on optimizing the traffic flow in VANET and analyzed the information collected at RSUs to make the routing decisions. Based on data analysis, re-routing was performed. This approach is not scalable and feasible by considering the real-time scenarios as they heavily depend on RSUs. The re-routing process is not adaptive and time-consuming with such an approach. The TIHOO routing solution was proposed in [34] for VANET using the cuckoo and improved fuzzy algorithms to address the problems of discovering stable and congestion-free paths. They used the vehicle speed, its moving direction, and geographical distance from the destination node as an input to the fuzzy logic system. The problem with this approach, the parameters selected are not effective enough to estimate the congestion around the vehicle and hence not reliable solution. High computational overhead resulted due to combined fuzzy logic and cuckoo search to discover the path. Finally, another most relevant study was presented in [35] in which mobility and bandwidth utilization parameters were used as input to the fuzzy logic system to estimate their congestion levels and accordingly the route established. But missing the link quality parameter in this approach may lead to not an effective congestion prediction solution for VANETs. Link quality is also an important parameter that helps to estimate the congestion level of vehicles efficiently and correctly in the network.

\section{B. Research Motivation and Contributions}

In the above works, we disclosed the problems with each approach introduced for congestion-aware routing and reliable route discovery. By considering such problems we motivated to introduce the novel routing solution called ACARP in this paper. For VANET safety applications, the key requirement is that vehicles should be capable of communicating with neighbouring vehicles with minimum computational overhead, communication delay, and data loss. The properties like high message rates, unreliable channel quality, and severe mobility lead to a significant problem for VANETs routing. The congestion control protocols [21-35] were designed to make sure the reliable transmission of security messages in V2V communications. However, adaptive congestion prediction and its utilization during the route discovery are missing in all works. In this paper, we formulate the problem of reducing the communication overhead, communication delay, packet loss, and 
emission control as the problem of congestion prediction of each vehicle adaptively. The outcome of congestion prediction can directly be utilized in the route discovery process to establish congestion-free and reliable paths with minimum efforts. The key contributions of ACARP are:

- Efficient and effective congestion prediction approach using the type-2 fuzzy logic algorithm in which the parameters like bandwidth occupation, link quality, and mobility of each vehicle used as input. It is a periodic and adaptive process and works in the background of routing without any extra overhead.

- For route discovery, the next forwarding vehicle has been selected by analyzing the congestion probability that is fetched directly from the routing table entries of each vehicle. The vehicle with a higher probability value (i.e. more reliable and less congested) was selected as the next hop. This approach is lightweight and does not require a specialized process.

- The extensive performance analysis of the proposed protocol with recent underlying methods is presented by considering the different network conditions and mobility patterns.

\section{ACARP Methodology}

As per the contributions described in the above section, this section presents the complete methodology of the planned ACARP protocol step-by-step. The functionality of the ACARP protocol consists of two main phases such as (1) periodic congestion prediction, and (2) safer and reliable data transmission. Figure 1 demonstrates the overall architecture of the ACARP protocol.

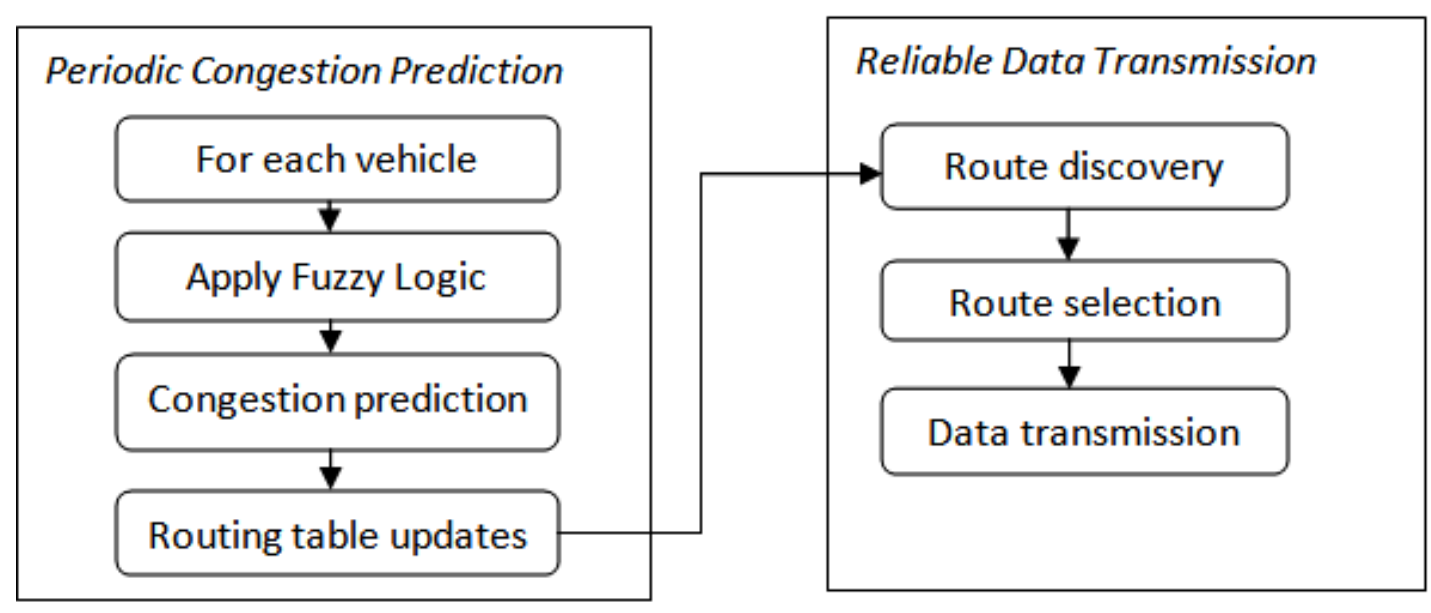

Figure 1. Architecture of ACARP protocol

As shown in figure 1, the first block is for periodic congestion prediction in which each vehicle is evaluated periodically using the AI approach type-2 fuzzy logic. The outcome of this phase is the prediction of the congestion status of each vehicle into routing table entries with its congestion probability value. The second block belongs to reliable data transmission in which the periodically updated congestion status and congestion probability values are directly utilized from the routing tables to establish safer and reliable routes for data transmission. After the route discovery, the first route was selected for data transmission among the particular source and destination 
vehicles in the network. The design and functionality of both blocks described in subsequent sections.

\section{A. Adaptive Congestion Prediction}

Figure 2 shows the working of proposed methodology for adaptive and periodic congestion prediction approach. Let's suppose that VANET deployed with $N$ number of vehicles in network that includes the set $V=\left\{v^{1}, v^{2}, \ldots v^{N}\right\}$. These $N$ number of vehicles are deployed in network of size $X \times Y$. As showing in figure 2, after VANET deployment, each vehicle $v, v \in V$ processed for the congestion prediction at current time $t$. The type-2Mamdani fuzzy logic is applied for prediction of congestion and to estimate current congestion probability $C P^{v}$ of vehicle $v$ in network at time $t$. Figure 3 showing the structure of proposed fuzzy logic system which is consisting of four phases such as fuzzification, a base of rules, inferences, and defuzzification. As shown in figure 3, outcome of fuzzy logic approach is digital value that represents congestion probability value $C P^{v}$ of vehicle $v$ at time $t$. This $C P^{v}$ value then compared with pre-defined threshold as showing in figure 2 . If $C P^{v}$ is greater than pre-defined threshold value, it means that node $v$ is non-congested and hence its status set to true (stat $=1)$, otherwise $v$ is congested and its status set to false $(s t a t=0)$ at time $t$. We modified the routing table entries of each vehicle in ACARP protocol by adding the outcome figure 2 periodically. In short, the $C P^{v}$ and stat values are periodically updated for each vehicle in their routing table entries. 


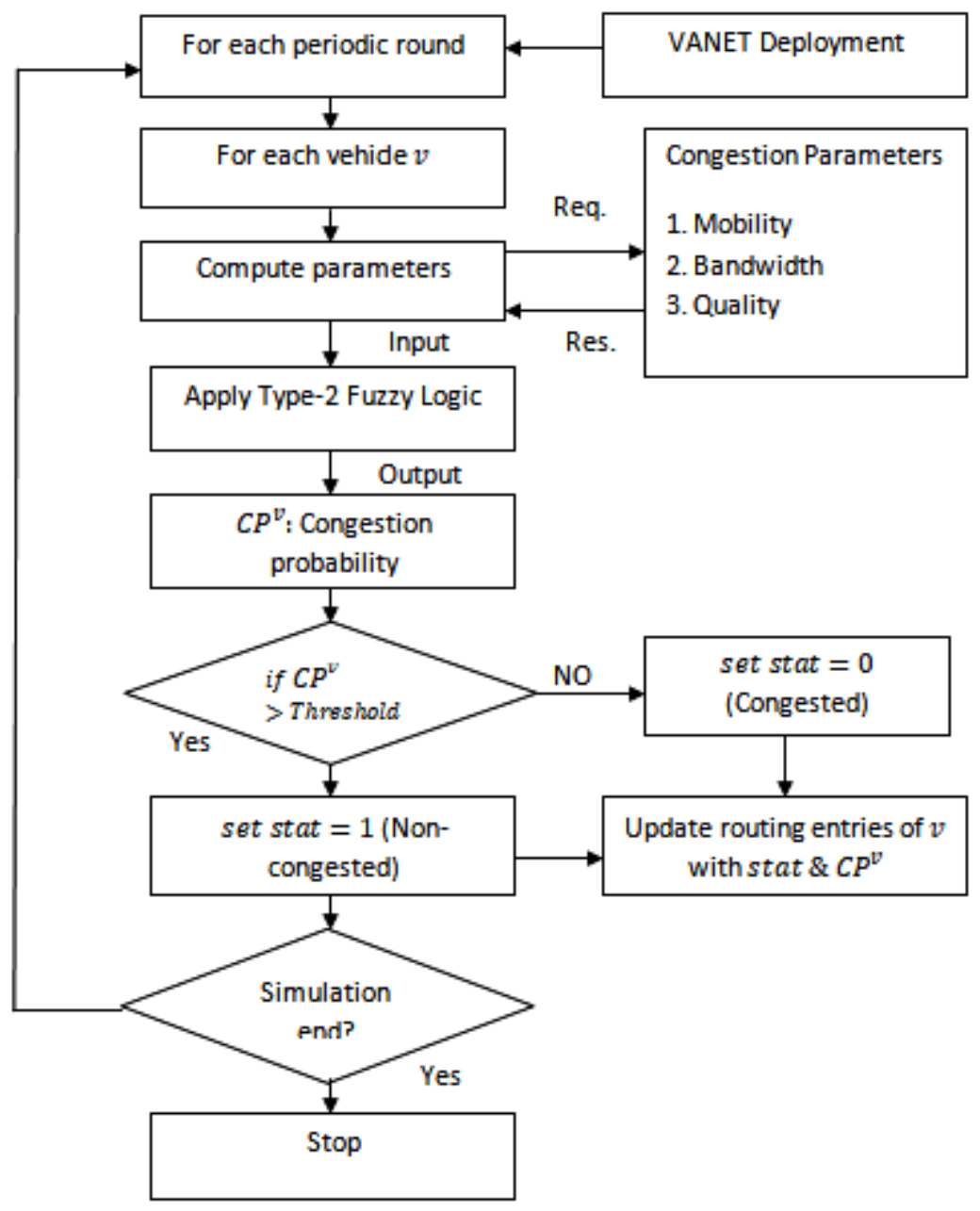

Figure 2. Adaptive congestion prediction using type-2 fuzzy logic approach

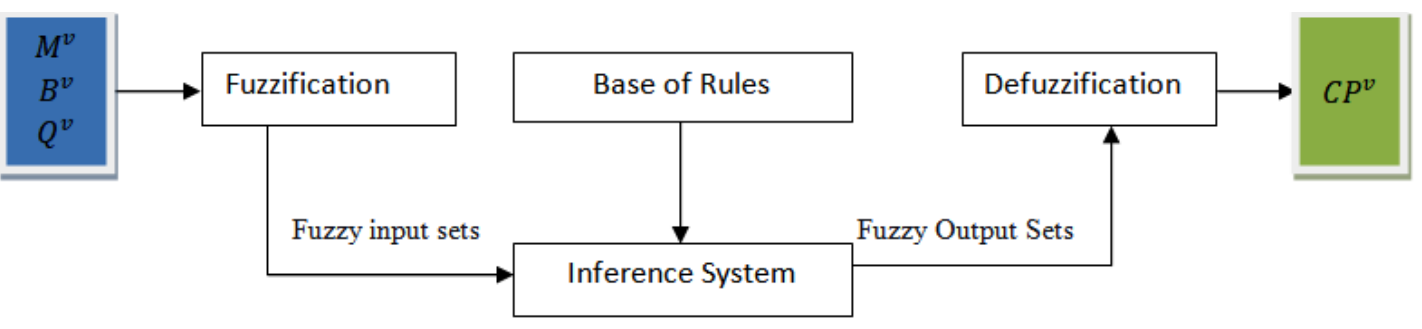

Figure 3. Proposed model of type-2 fuzzy Mamdani fuzzy logic method

I. Fuzzification: As showing in figure 3, the first step of type-2 fuzzy model for congestion prediction is the fuzzification in which the singleton fuzzifier used. It takes three inputs of each vehicle $v$ such as mobility speed $\left(M^{v}\right)$, bandwidth occupancy $\left(B^{v}\right)$, and link quality $\left(Q^{v}\right)$ at current time $t$. We extracted these values for each vehicle periodically in range of $[0,1]$ for sake of convenience. Before discussing the fuzzification process, how these three parameters of each vehicle computed presented.

Mobility Speed: For VANETs, mobility is an important parameter as it leads to routing challenges due to its severe mobility speed. Thus, the first parameter to 
estimate the congestion probability is the mobility speed of the vehicle. The current mobility speed of vehicle $v$ at time $t$ is estimated as:

$M^{v}=1-\left(\frac{\text { mobility }(v, t)}{200}\right)$

Where, mobility $(v, t)$ function returns the current moving speed of vehicle $v$ at time $t$. The value $200 \mathrm{~km} / \mathrm{hr}$ is maximum mobility speed assumed for each vehicle in network. The outcome of $M^{v}$ is in range of 0 to 1 . It represented as higher the $M^{v}$, then lower the mobility speed and lower chances of congestion of $v$.

Bandwidth Occupancy: This is the vital parameter to estimate the current congestion on vehicle $v$. The computation of $M^{v}$ is very much similar to mobility speed. It is computed as:

$B^{v}=1-\left(\frac{\text { bandwidt } h(v, t)}{2048}\right)$

Where, $\operatorname{bandwidth}(v, t)$ function returns the bandwidth allocated of vehicle $v$ at time $t$. The value $2048 \mathrm{kbps}$ is maximum allowed bandwidth for each vehicle in network. The outcome of $B^{v}$ is in range of 0 to 1 that represents higher the $B^{v}$, then higher bandwidth available and lower congestion chances of $v$.

Link Quality: Above both parameters deals with just routing layer, however, congestion can be created at MAC layer as well. To achieve the reliable solutions, we computed the link quality $Q^{v}$ of each vehicle $v$ at MAC layer. It is computed as:

$Q^{v}=\frac{\operatorname{recv}(v, t-1, t)}{\operatorname{expt}(v, t-1, t)}$

Where $\operatorname{recv}(v, t-1, t)$ and $\operatorname{expt}(v, t-1, t)$ total number of packets received and expected respectively at vehicle $v$ during the time interval $(t-1, t)$. Higher $Q^{v}$ value leads to lower congestion at $v$.

In this way we get the input values $M^{v}, B^{v}$, and $Q^{v}$ of vehicle $v$ at time $t$ input for fuzzification. At fuzzification phase, these three variables divided into three categories as per their values such as: high, medium, and low. Table 1 demonstrates how input parameters divided as per their current value. This categorization leads to significant reduction in network overhead. Thus, for each parameter, the fuzzy input set includes either "high", "medium", or "low". For example, if the outcome of variables $M^{v}, B^{v}$, and $Q^{v}$ of vehicle $v$ at time $t$ is $0.4,0.21$, and 0.8 respectively, then the fuzzy input set consists of \{"medium", "low", "high"\}.

Table 1. Categorization of input variables in fuzzification

\begin{tabular}{|c|c|c|c|}
\hline Variable & "high" & "medium" & "low" \\
\hline Mobility & $M^{v} \leq 0.25$ & $M^{v}>0.25 \& \& M^{v} \leq 0.75$ & $M^{v} \geq 0.75$ \\
\hline $\begin{array}{l}\text { Bandwidth } \\
\text { Occupancy }\end{array}$ & $M^{v} \leq 0.25$ & $M^{v}>0.25 \& \& M^{v} \leq 0.75$ & $M^{v} \geq 0.75$ \\
\hline Link quality & $M^{v} \geq 0.75$ & $M^{v}>0.25 \& \& M^{v} \leq 0.75$ & $M^{v} \leq 0.25$ \\
\hline
\end{tabular}


II. Base of Rules: As per the fuzzy input sets, we designed total 27 rules in IFTHEN format. Table 2 shows the complete set of rules that demonstrates the three input fuzzy variables and one out numerical variable. That numerical variable represents the congestion probability $C P^{v}$ of vehicle $v$ at time $t$. As demonstrated in table 2, the scalable and rich set of rules designed to address the accurate congestion detection and decision on congestion probability of each vehicle by balancing all three input parameters. From these rules, it is noticed that more weight is given to the bandwidth occupancy and link quality, as these two widely correlates the congestion in the network.

Table 2. Base of rules

\begin{tabular}{|c|c|c|c|c|}
\hline Rule No. & $M^{v}$ & $B^{v}$ & $Q^{v}$ & $C P^{v}$ \\
\hline 1. & "high" & "high" & "low" & 0.25 \\
\hline 2. & "high" & "high" & "medium" & 0.25 \\
\hline 3. & "high" & "high" & "high" & 0.4 \\
\hline 4. & "high" & "medium" & "low" & 0.25 \\
\hline 5. & "high" & "medium" & "medium" & 0.6 \\
\hline 6. & "high" & "medium" & "high" & 0.75 \\
\hline 7. & "high" & "low" & "low" & 0.4 \\
\hline 8. & "high" & "low" & "medium" & 0.7 \\
\hline 9. & "high" & "low" & "high" & 0.8 \\
\hline 10. & "high" & "high" & "low" & 0.25 \\
\hline 11. & "high" & "medium" & "low" & 0.25 \\
\hline 12. & "high" & "low" & "low" & 0.4 \\
\hline 13. & "high" & "high" & "medium" & 0.25 \\
\hline 14. & "high" & "medium" & "medium" & 0.6 \\
\hline 15. & "high" & "low" & "medium" & 0.75 \\
\hline 16. & "high" & "high" & "high" & 0.25 \\
\hline 17. & "high" & "medium" & "high" & 0.6 \\
\hline 18. & "high" & "low" & "high" & 0.4 \\
\hline 19. & "high" & "high" & "low" & 0.25 \\
\hline 20. & "medium" & "high" & "low" & 0.25 \\
\hline 21. & "low" & "high" & "low" & 0.25 \\
\hline 22. & "high" & "medium" & "medium" & 0.5 \\
\hline 23. & "medium" & "medium" & "medium" & 0.7 \\
\hline 24. & "low" & "medium" & "medium" & 0.8 \\
\hline 25. & "high" & "low" & "high" & 0.5 \\
\hline 26. & "medium" & "low" & "high" & 0.8 \\
\hline 27. & "low" & "low" & "high" & 0.9 \\
\hline
\end{tabular}

III. Inference System: It is the type-2 fuzzy decision-making block where the fuzzy input sets mapped with the set of rules defined in table 2. As the second phase presented a rich set of rules in table 2, those are applied in the decision-making process to estimate the congestion probability of the vehicle and intended to guide the final fuzzy value. In short, the fuzzy decisions are generated in this phase through 
the rules available in the rule base. The output of this phase is the numerical fuzzy decision value for each vehicle fuzzy input set.

IV. Defuzzification: This is final phase of type-2 fuzzy logic system which takes input as output fuzzy sets and then performs the defuzzification to estimate the final prediction of congestion status of vehicle $v$. In this phase, as per the outcome value $C P^{v}$ of third phase, the post-processing operations performed such as checking against the threshold and routing table updations. The statusstat of congestion for vehicle $v$ at time $t$ is estimated:

stat $=\left\{\begin{array}{rr}1, & C P^{v}>\text { threshold } \\ 0, & \text { Otherwise }\end{array}\right.$

It means that higher the value of $C P^{v}$, higher the reliable vehicle and less congestion at time $t$. After significant number of experiments and observations, we set the threshold value in this work as 0.38 for QoS improvement and $\mathrm{CO} 2$ emissions. The entire process of adaptive and periodic congestion prediction is presented in algorithm 1 .

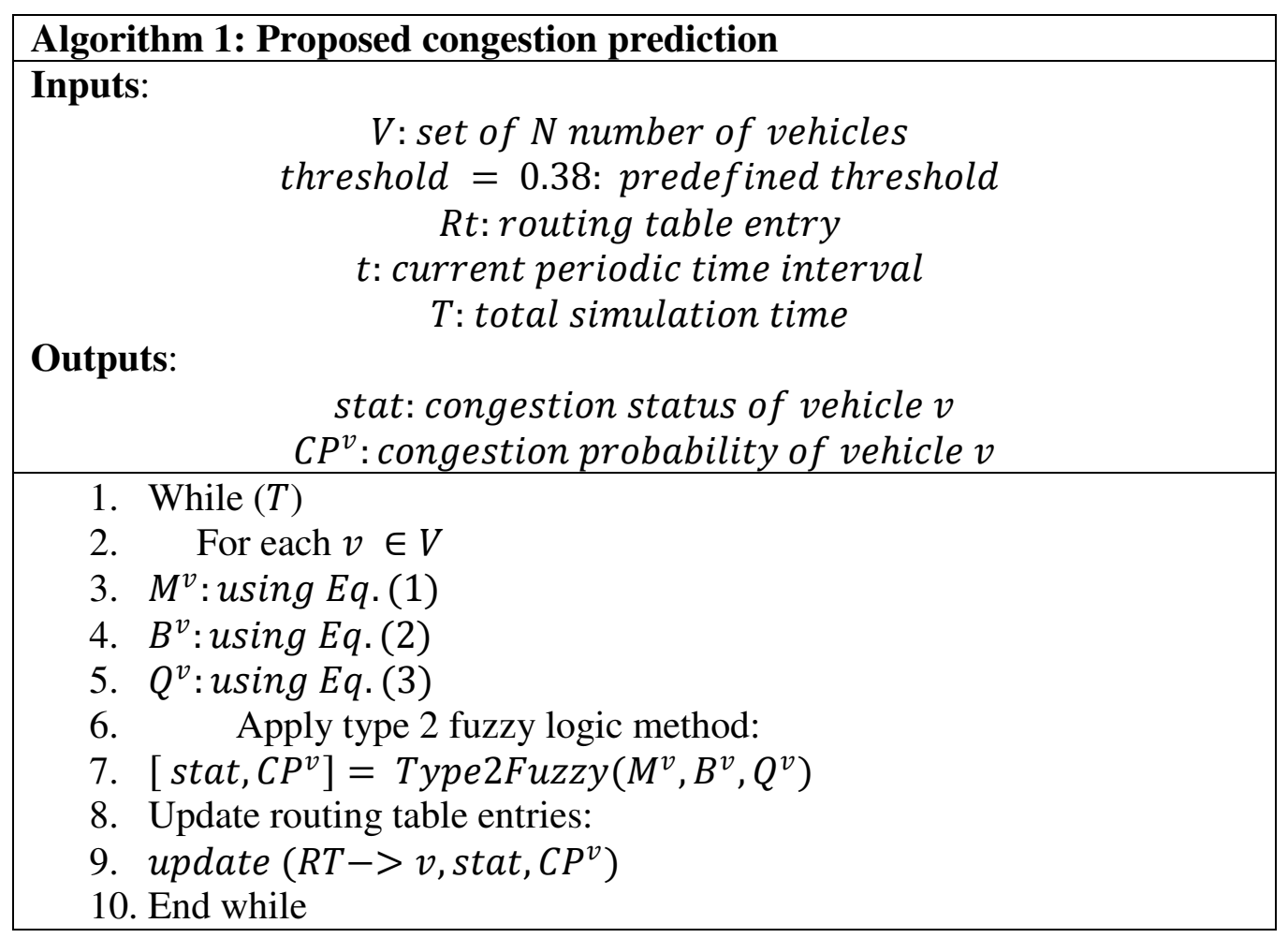

\section{B. Safe and Reliable Data Transmission}

The second phase of ACARP protocol belongs to the lightweight and reliable data transmission algorithm. It is lightweight approach as there is no specialized functionality applied to discover the reliable and safe next hop data forwarder vehicle among the particular source $(S)$ and destination $(D)$ pair in network. The route discovery initiated by source $S$ towards destination $D$. The proposed route discovery approach analyze the neighbouring vehicles according to its current 
congestion stat and congestion probability value $C P^{v}$. As these values are periodically updated for each vehicle in their routing table entries, during the route discovery we directly extract and analyze to choose the best and reliable data forwarder node among $S$ and $D$ pair. As showing functionality of proposed route discovery and data transmission in algorithm 2, the next hop node first checked against its current stat, if the stat is 1 , then it is consider as candidate for data forwarding otherwise it is discarded. Once all the eligible candidates discovered, the one with higher $C P^{v}$ selected as next hop forwarder.

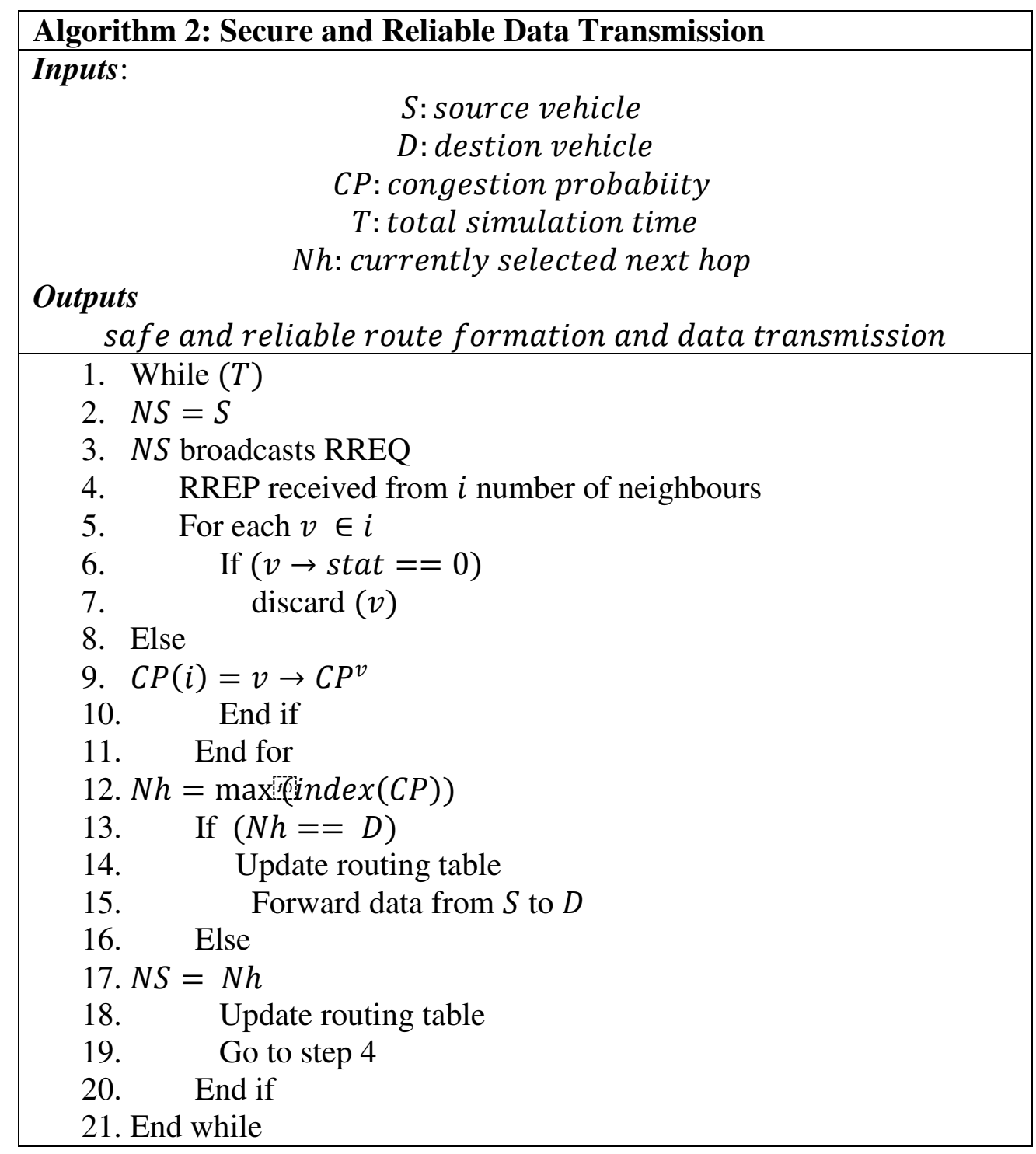

\section{Simulation Results and Discussions}

This section presents the experimental results and analysis of the proposed ACARP protocol for VANET using different kinds of network scenarios. ACARP protocol is implemented and evaluated using the NS2 tool for two network scenarios like mobility and density variations. The performance of ACARP protocol is measured in five performance metrics such as average throughput, communication delay 
(latency), PDR, communication overhead, and $\mathrm{CO} 2$ emission. These parameters are evaluated compared to two recent fuzzy-logic based route discovery and congestion aware routing methods for VANETS such as TIHOO [34] and FBVANET [35]. The main reasons for selecting these two protocols for comparative study are (1) recently proposed protocols for VANET, (2) congest-aware routing, (3) fuzzy-logic approach to discover the reliable routes by detecting the congestions.

The network scenarios for performance evaluations are demonstrated in tables 3 and 4 for mobility and density variations respectively. For performance evaluation, two different mobility models are used like random walk and the Manhattan grid for mobility and density scenarios respectively. These mobility patterns generated using the open-source VANET mobility generator called BonnMotion [36] tool. IEEE $802.11 \mathrm{p}$ protocol used for VANET scenarios of size $8000 \times 8000$. Total simulation time is 500 seconds along with $6 \mathrm{CBR}$ communication patterns. In the mobility scenario, mobility varying from $40 \mathrm{Km} / \mathrm{hr}$ to $90 \mathrm{Km} / \mathrm{hr}$. In the density scenario, the number of vehicles varying from 50 to 300 . The performance metrics computed as per the standard formulations except for the $\mathrm{CO} 2$ emission. To the best of our knowledge, this is the first time $\mathrm{CO} 2$ emission of VANET simulations computed. The average $\mathrm{CO} 2$ emission of the network computed by utilizing the data loss parameter as:

CO2 emission $=\frac{L * 144.15}{S T}$

Where, $L$ is total number of packets dropped in network and $S T$ is total simulation time. Section A presents the simulation results for mobility scenarios and section B presents simulation results for density scenarios.

Table 3. Parameters of mobility evaluations

\begin{tabular}{|c|c|}
\hline Number of vehicles & 150 \\
\hline Routing Methods & TIHOO, FBVANET, ACARP \\
\hline Simulation Time & 500 second \\
\hline Mobility (Km/hr) & Two-Ray Ground \\
\hline MAC & 8000 x 8000 meter \\
\hline Propagation Model & Random Walk Model \\
\hline Area & Omni Antenna \\
\hline Mobility & $144.15 \mathrm{~g} / \mathrm{km}$ \\
\hline Antenna & CBR \\
\hline CO2 model & \\
\hline Traffic pattern & $\mathrm{hr}$ \\
\hline & \\
\hline
\end{tabular}


Table 4. Parameters for density evaluations

\begin{tabular}{|c|c|}
\hline Number of vehicles & $50,100,150,200,250,300$ \\
\hline Routing Methods & TIHOO, FBVANET, ACARP \\
\hline Simulation Time & 500 seconds \\
\hline Mobility $(\mathrm{Km} / \mathrm{hr})$ & $802.11 \mathrm{p}$ \\
\hline MAC & Two-Ray Ground \\
\hline Propagation Model & 8000 x 8000 meter \\
\hline Area & Manhattan grid mobility \\
\hline Mobility & Omni Antenna \\
\hline Antenna & $144.15 \mathrm{~g} / \mathrm{km}$ \\
\hline CO2 model & CBR \\
\hline Traffic pattern & \\
\hline
\end{tabular}

\section{A. Mobility Evaluations}

The purpose of evaluating the mobility variations is to assess the reliability of the proposed ACARP protocol compared to existing protocols under low to high dynamics of the vehicle and hence VANET topology. Figures 4 to 8 exhibit the results of normal throughput, PDR, CO2 emanation, correspondence deferral, and overhead individually. The results show that ACARP can enhance all the parameters compared to both recent protocols. The results of average throughput (figure 4) and PDR (figure 5) demonstrates a similar trend for mobility variations of each protocol. It is noticed that as mobility increased, the performance of throughput and PDR decreased. This is due to an increased number of routes establishment tasks with increased mobility speed of vehicles. These results define the impact of mobility of VANET performance as well. 


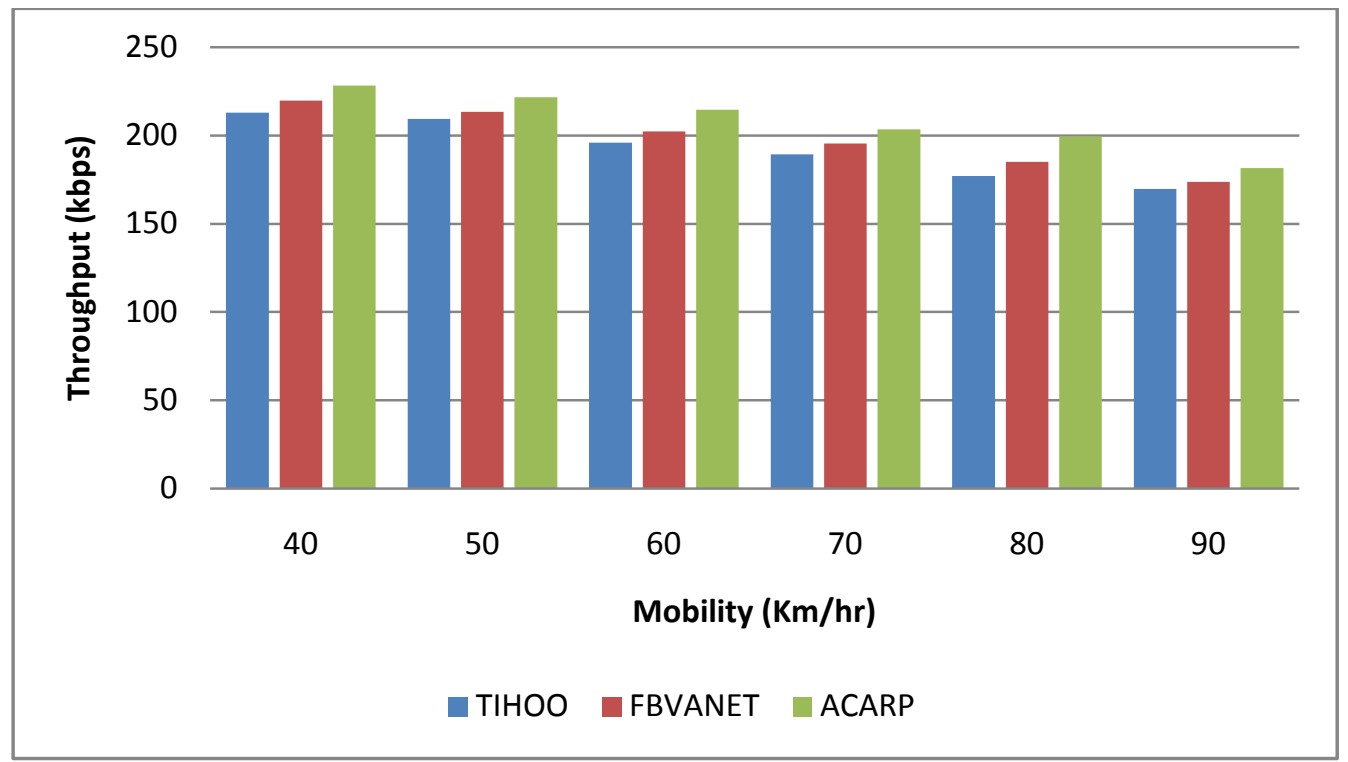

Figure 4. Throughput performance evaluations in mobility scenario

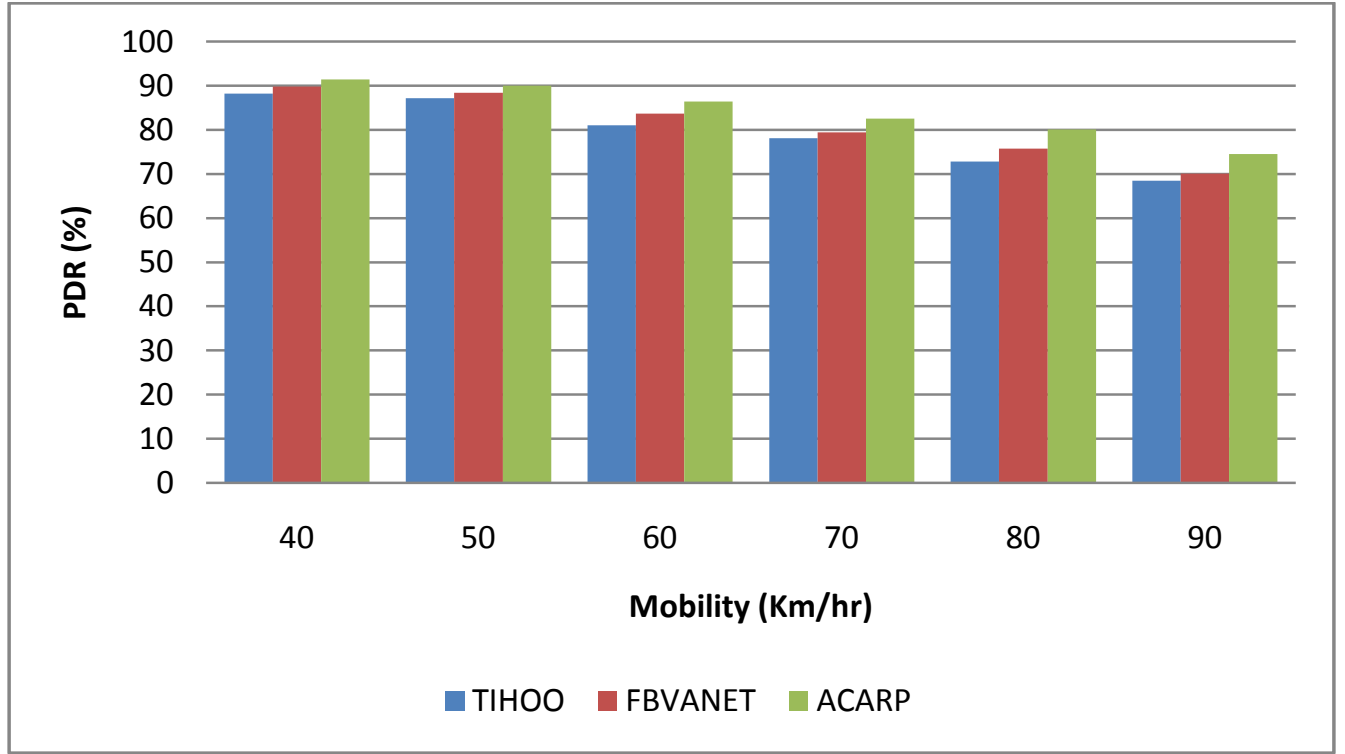

Figure 5. PDR performance evaluations in mobility scenario

Among all protocols, the proposed protocol significantly improved the throughput by $10 \mathrm{kbps}$ and PDR by $3 \%$. The improvement is estimated by average performances (Table 5). The ACARP can able to improve throughput and PDR due to adaptive and periodic functionality of congestion prediction and its direct utilization during the reliable route discovery phase. Also the appropriate selection of congestion parameters such as mobility speed, bandwidth occupancy, and link quality boosts the accurate congestion prediction in the network that helps to minimize the data loss.

Furthermore, the $\mathrm{CO} 2$ emissions results demonstrate a significant reduction in pollutions using ACARP in urban areas due to reduced congestions/traffics and hence travelling time. As mobility increased, the $\mathrm{CO} 2$ emission $(\mathrm{g} / \mathrm{km})$ increased as well. It is due to increased routing functionalities that lead to congestions and data 
loss in the network. In this paper, we formulated the problem of congestion with pollutions; it means that higher congestions lead to excessive $\mathrm{CO} 2$ emissions. Due to problems mentioned earlier about existing protocols TIHOO and FBVANET, the $\mathrm{CO} 2$ emissions results not much promising to them compared to proposed ACARP. The ACARP reduced the CO2 emissions approximately by $35 \mathrm{~g} / \mathrm{km}$ compared to TIHOO and FBVANET protocols.

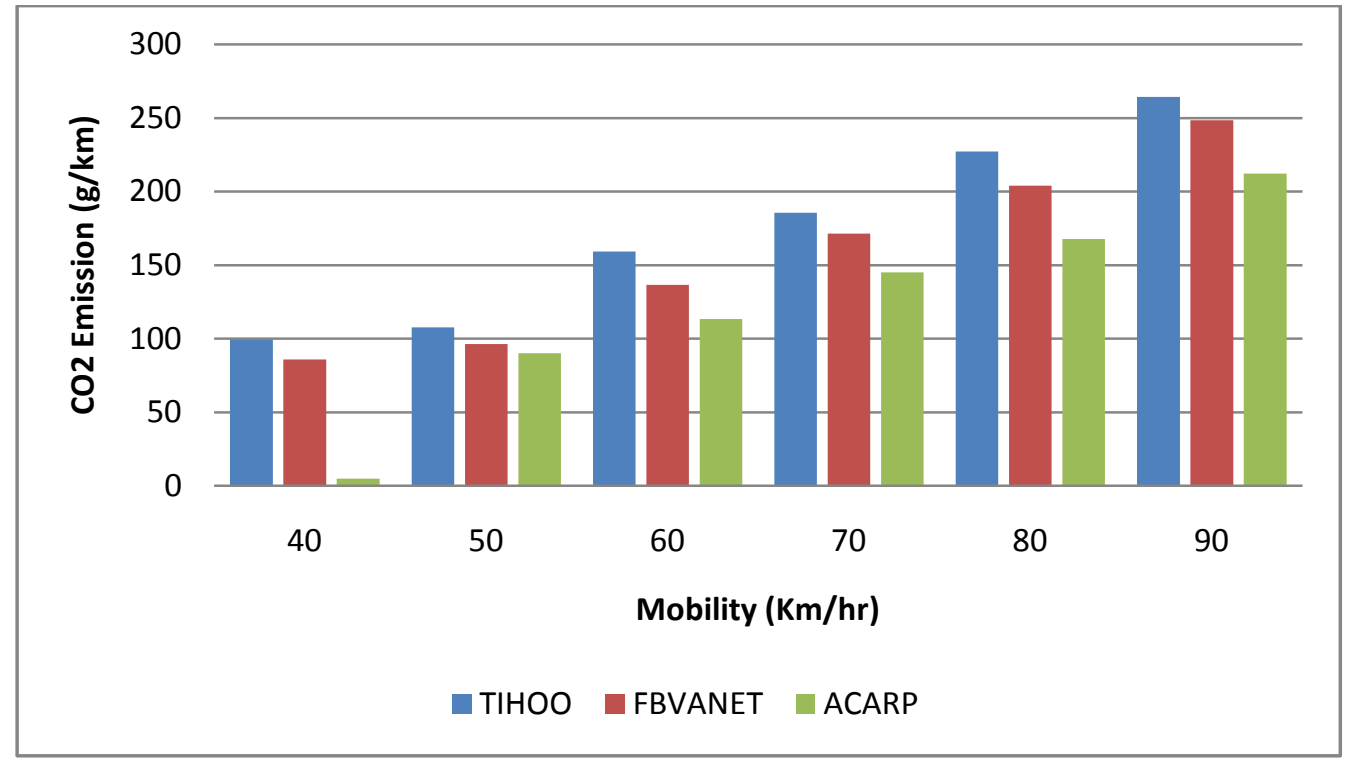

Figure 6. $\mathrm{CO} 2$ emission performance evaluations in mobility scenario

The results of delay (figure 7) and communication overhead (figure 8) demonstrate correlation to each other as they mainly depend on the process of data transmissions in highly dynamic networks. The proposed method achieved the minimum overhead compared to TIHOO and FBVANET because ACARP focused not only on safer routes but also reduced route discovery time by utilizing periodically computed congestion status and congestion probability value. This functionality is missing in TIHOO and FBVANET that leads to high delay and communication overhead. ACARP shows the reduction in both delay and communication overhead parameters (Demonstrated in table 5). 


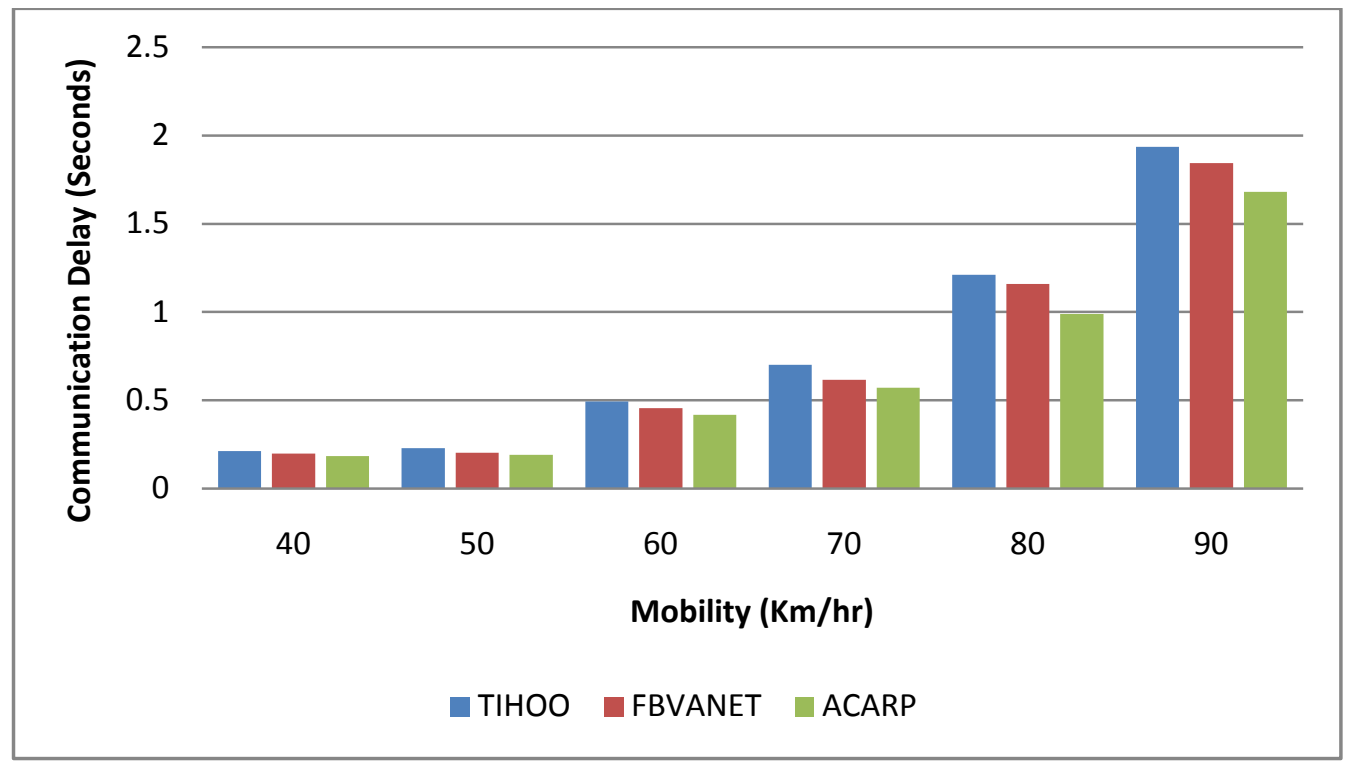

Figure 7. Communication delay performance evaluations in mobility scenario

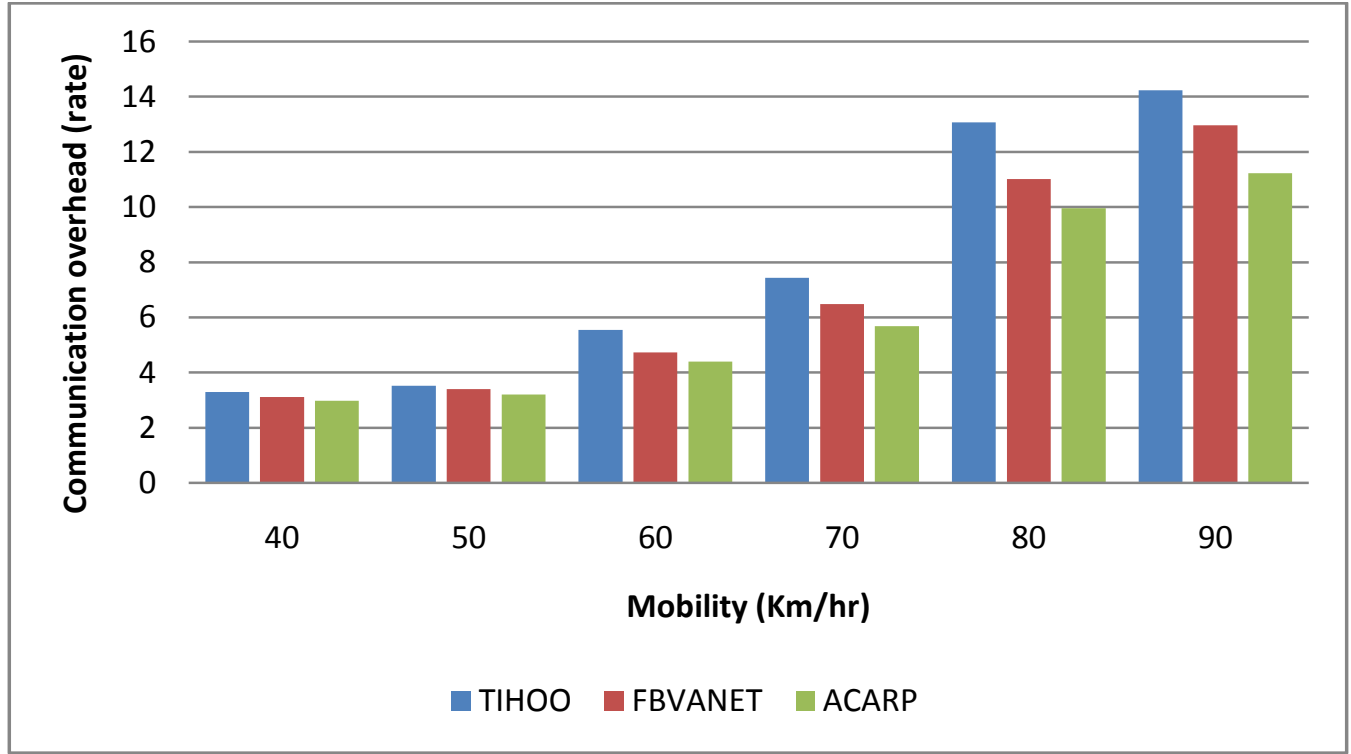

Figure 8. Communication overhead performance evaluations in mobility scenario

Table 5. Average mobility scenario performance

\begin{tabular}{|c|c|c|c|}
\hline & TIHOO & FBVANET & ACARP \\
\hline Throughput & 192.45 & 198.27 & 208.21 \\
\hline PDR & 79.3 & 81.19 & 84.14 \\
\hline CO2 emission & 173.82 & 157.07 & 122.21 \\
\hline Delay & 0.7972 & 0.7461 & 0.6722 \\
\hline Overhead & 7.84 & 6.94 & 6.24 \\
\hline
\end{tabular}

\section{B. Density Evaluations}


The reliability and robustness of the protocol of VANET can also be validated by density parameters i.e. small to a large number of vehicles. This section presents the simulation results for a varying number of vehicles using each protocol for each parameter.

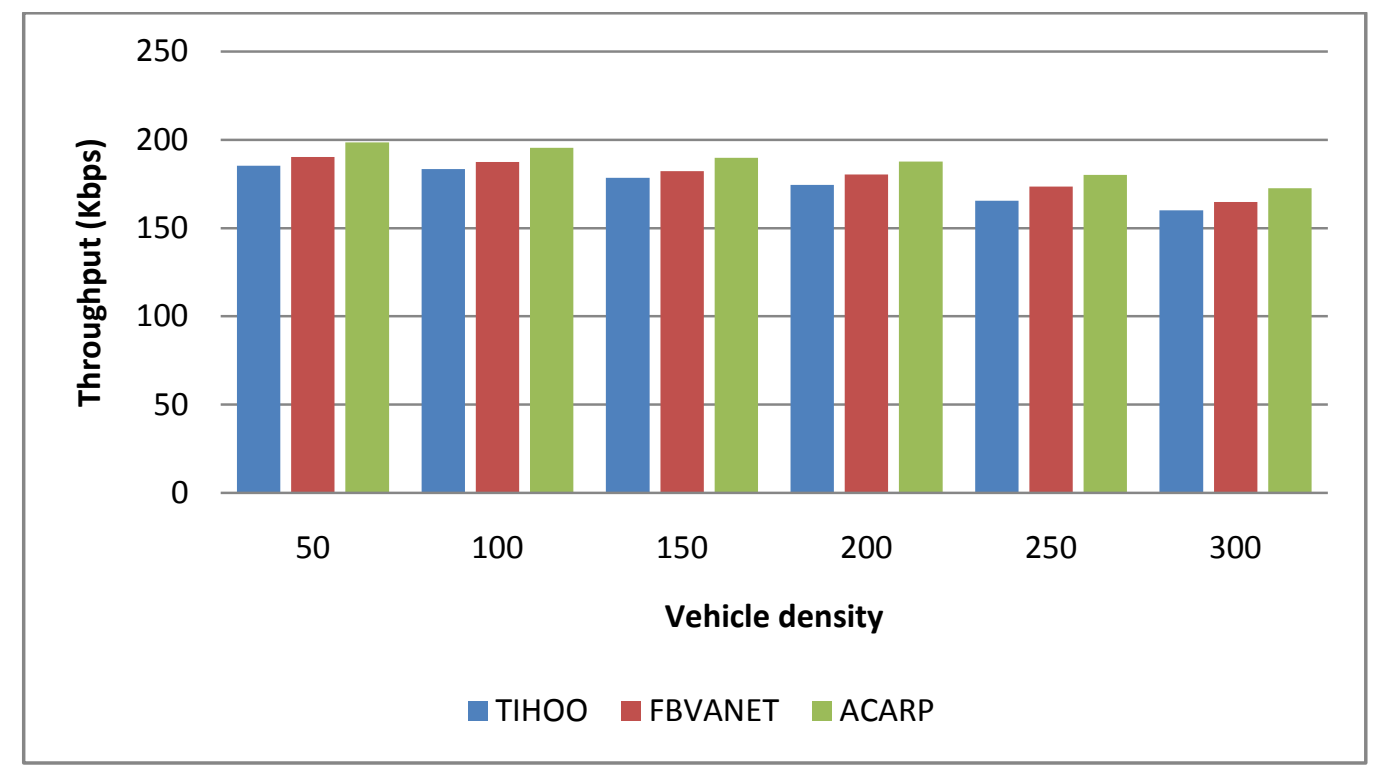

Figure 9. Throughput performance evaluations in density scenario

The performance of throughput (figure 9) and PDR (figure 10) demonstrates that with an increased number of vehicle density, the performance decreased. The main reason for this case is that an increased number of vehicles leads to longer data transmission a path that increases the congestion level and data loss in the network. The impact of increased density is observed in all other parameters as well (figures 11, 12, and 13). Among the three protocols, ACARP again shows the improvement in throughput and PDR performances. In ACARP three parameters (mobility speed, bandwidth occupancy, and link quality) that directly responsible for congestion and reliability of vehicles in the network utilized effectively compared to TIHOO and FBVANET. Secondly, the periodic and adaptive process of congestion prediction and it is dynamically updating in routing tables leads to direct utilization during the route discovery process. These characteristics of ACARP put ahead of both existing TIHOO and FBVANT protocols. 


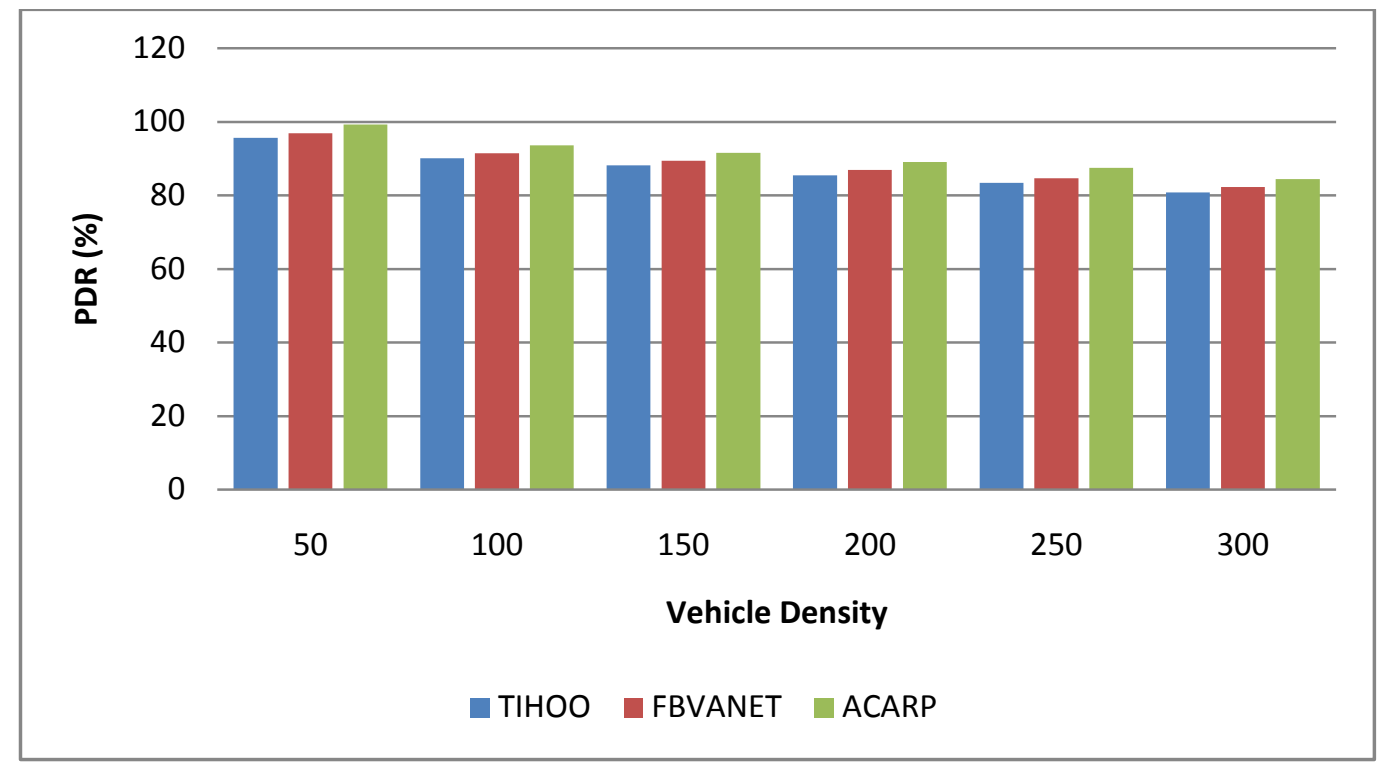

Figure 10. PDR performance evaluations in density scenario

The $\mathrm{CO} 2$ emission performance further demonstrated a significant reduction for density scenarios as well as using the proposed ACARP protocol. Reduction in packets dropped (PDR performance) directly related to a reduction in $\mathrm{CO} 2$ emissions. The fuzzy-based adaptive congestion prediction approach in ACARP able to minimize the congestion levels in the network effectively compared to TIHOO and FBVANET. Both TIHOO and FBVANT mainly focused on discovering reliable paths among source and destination pairs rather than predicting the congestion levels. It takes a long time to discover routes and data transmission for TIHOO and FBVANET compared to ACARP protocol. Among TIHOO and FBVANET, the TIHOO protocol shows the worst performance compared to FBVANET. TIHOO used the non-congestion aware parameters (speed, geographical distance, vehicle moving directions) to discover the reliable route. They used a combined approach of fuzzy logic and cuckoo search to discover the route which takes more computation efforts as well. In FBVANET, the bandwidth and mobility speed of each vehicle passed as input to the fuzzy logic model to build the reliable paths. 


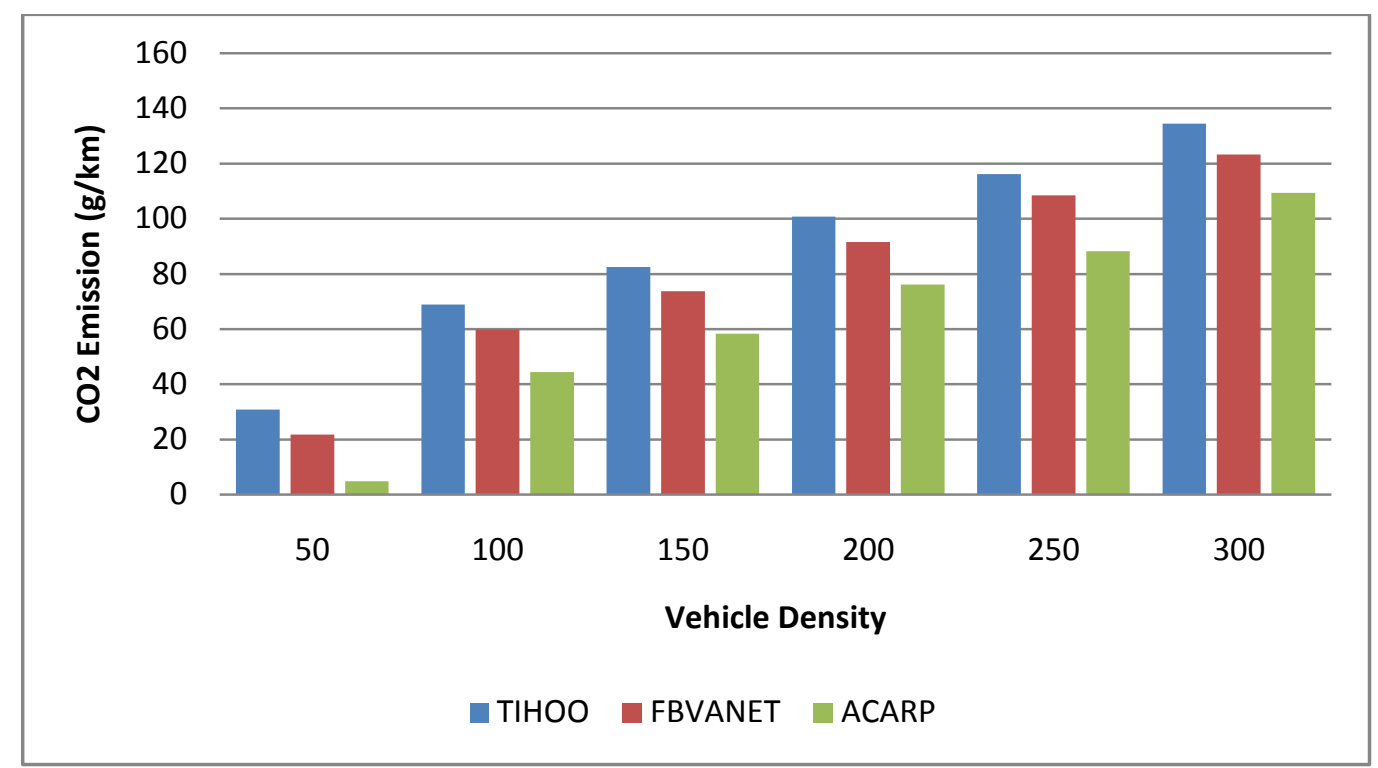

Figure 11. CO2 emission performance evaluations in density scenario

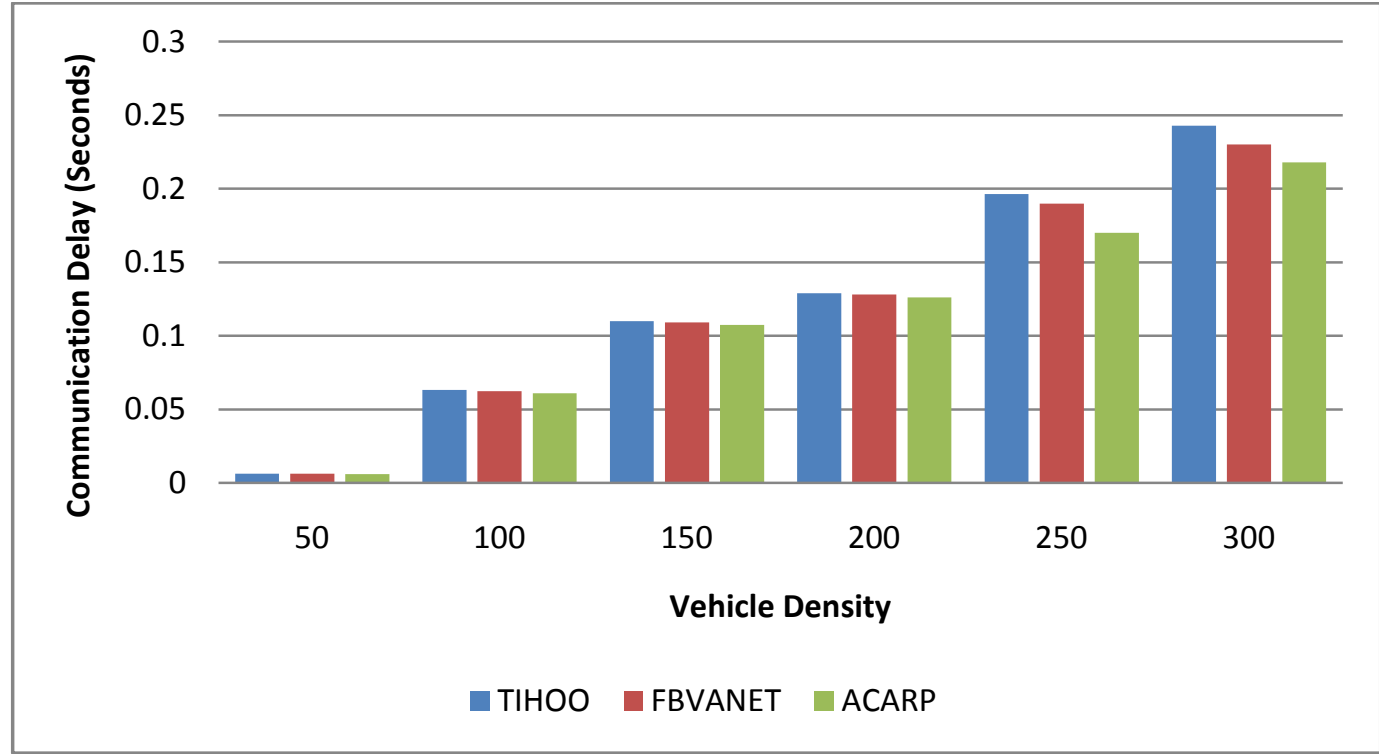

Figure 12. Communication delay performance evaluations in density scenario

Finally, figures 12 and 13 demonstrated the outcomes of communication delay and overhead for each protocol. The results show the promising for the proposed ACARP protocol compared to TIHOO and ACARP. Table 6 shows the average performances for each parameter using each protocol. For density scenarios, throughput performance improved approximately by $8 \mathrm{kbps}$, PDR increased by $2 \%$, $\mathrm{CO} 2$ reduced by $16 \mathrm{~g} / \mathrm{km}$, delay reduced approximately by 0.01 second, and communication overhead reduced by 0.17 rate. 


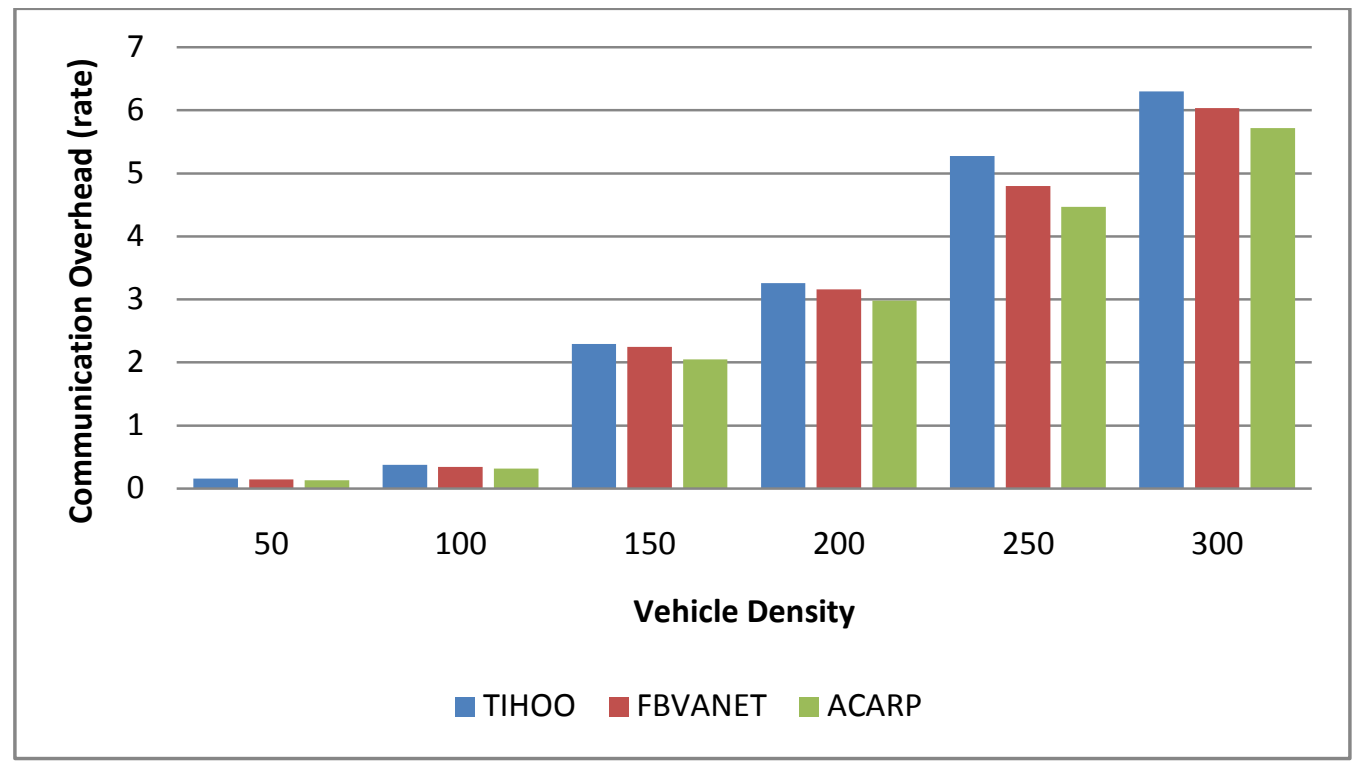

Figure 13. Communication overhead performance evaluations in density scenario

Table 6. Average density scenario performance

\begin{tabular}{|c|c|c|c|}
\hline & TIHOO & FBVANET & ACARP \\
\hline Throughput & 174.51 & 179.75 & 187.25 \\
\hline PDR & 87.25 & 88.59 & 90.92 \\
\hline CO2 emission & 88.96 & 79.77 & 63.56 \\
\hline Delay & 0.1245 & 0.1209 & 0.1147 \\
\hline Overhead & 2.94 & 2.78 & 2.61 \\
\hline
\end{tabular}

\section{Conclusion and Future Directions}

This paper proposed the novel steering convention for VANET called ACARP. The purpose of ACARP is to predict the congestions in VANET using the AI method and utilize the outcome that prediction for safer and reliable route formation. High congestion in VANET leads to higher delays, travelling time, a higher $\mathrm{CO} 2$ emission that harms human beings. Thus, we formulated the problem of $\mathrm{CO} 2$ emission reduction by employing the congestion reduction in VANET. The design of the ACARP protocol is two-fold in which periodically congestion prediction performed using the type-2 fuzzy model and lightweight reliable route discovery performed by utilizing the congestion prediction outcomes directly. Three parameters of each vehicle were used as input for congestion prediction like mobility speed, bandwidth occupancy, and link quality. Simulation results claim that ACARP improved the throughput and PDR performances, reduced communication delay, communication overhead, and $\mathrm{CO} 2$ emissions compared to recent protocols. For prospect direction, we recommend: (1) investigating the ACARP protocol for different kinds of traffic patterns, (2) the use of a nature-inspired algorithm for route discovery to optimize the performance further.

\section{References}


1. Fotros M., Rezazadeh J., Ameri Sianaki O. (2020) A Survey on VANETs Routing Protocols for IoT Intelligent Transportation Systems. In: Barolli L., Amato F., Moscato F., Enokido T., Takizawa M. (eds) Web, Artificial Intelligence and Network Applications. WAINA 2020. Advances in Intelligent Systems and Computing, vol 1150. Springer, Cham. https://doi.org/10.1007/978-3-030-44038-1_102.

2. Mahajan, H.B., \& Badarla, A. (2019). Experimental Analysis of Recent Clustering Algorithms for Wireless Sensor Network: Application of IoT based Smart Precision Farming. Jour of Adv Research in Dynamical \& Control Systems, Vol. 11, No. 9. 10.5373/JARDCS/V1119/20193162.

3. Xiao L., Zhuang W., Zhou S., Chen C. (2019) Introduction. In: Learningbased VANET Communication and Security Techniques. Wireless Networks. Springer, Cham. https://doi.org/10.1007/978-3-030-01731-6_1.

4. Nassar L. et al. (2012) Vehicular Ad-hoc Networks(VANETs): Capabilities, Challenges in Context-Aware Processing and Communication Gateway. In: Kamel M., Karray F., Hagras H. (eds) Autonomous and Intelligent Systems. AIS 2012. Lecture Notes in Computer Science, vol 7326. Springer, Berlin, Heidelberg. https://doi.org/10.1007/978-3-642-31368-4_6.

5. Giripunje L.M., Masand D., Shandilya S.K. (2021) Congestion Control in Vehicular Ad-Hoc Networks (VANET's): A Review. In: Abraham A., Shandilya S., Garcia-Hernandez L., Varela M. (eds) Hybrid Intelligent Systems. HIS 2019. Advances in Intelligent Systems and Computing, vol 1179. Springer, Cham. https://doi.org/10.1007/978-3-030-49336-3_26.

6. Mahajan, H.B., Badarla, A. \& Junnarkar, A.A. (2020). CL-IoT: cross-layer Internet of Things protocol for intelligent manufacturing of smart farming. J Ambient Intell Human Comput. https://doi.org/10.1007/s12652-020-02502-0.

7. Eze, E.C., Zhang, S., Liu, E. et al. Advances in vehicular ad-hoc networks (VANETs): Challenges and road-map for future development. Int. J. Autom. Comput.13, 1-18 (2016). https://doi.org/10.1007/s11633-015-0913-y.

8. Golestan K. et al. (2012) Vehicular Ad-hoc Networks(VANETs): Capabilities, Challenges in Information Gathering and Data Fusion. In: Kamel M., Karray F., Hagras H. (eds) Autonomous and Intelligent Systems. AIS 2012. Lecture Notes in Computer Science, vol 7326. Springer, Berlin, Heidelberg. https://doi.org/10.1007/978-3-642-31368-4_5.

9. Amadeo, M., Campolo, C., Molinaro, A., \& Ruggeri, G. (2009). A WAVECompliant MAC Protocol to Support Vehicle-to-Infrastructure Non-Safety Applications. 2009 IEEE International Conference on Communications Workshops. doi:10.1109/iccw.2009.5208067.

10. Baras S., Saeed I., Tabaza H.A., Elhadef M. (2018) VANETs-Based Intelligent Transportation Systems: An Overview. In: Park J., Loia V., Yi G., Sung Y. (eds) Advances in Computer Science and Ubiquitous Computing. CUTE 2017, CSA 2017. Lecture Notes in Electrical Engineering, vol 474. Springer, Singapore. https://doi.org/10.1007/978-981-10-7605-3 44.

11. Zeadally, S., Hunt, R., Chen, Y. et al. Vehicular ad hoc networks (VANETS): status, results, and challenges. Telecommun Syst 50, 217-241 (2012). https://doi.org/10.1007/s11235-010-9400-5.

12. Gaikwad D.S., Zaveri M. (2011) VANET Routing Protocols and Mobility Models: A Survey. In: Wyld D.C., Wozniak M., Chaki N., Meghanathan N., 
Nagamalai D. (eds) Trends in Network and Communications. WeST 2011, NeCoM 2011, WiMoN 2011. Communications in Computer and Information Science, vol 197. Springer, Berlin, Heidelberg. https://doi.org/10.1007/978-3642-22543-7_34.

13. Fotros M., Rezazadeh J., Ameri Sianaki O. (2020) A Survey on VANETs Routing Protocols for IoT Intelligent Transportation Systems. In: Barolli L., Amato F., Moscato F., Enokido T., Takizawa M. (eds) Web, Artificial Intelligence and Network Applications. WAINA 2020. Advances in Intelligent Systems and Computing, vol 1150. Springer, Cham. https://doi.org/10.1007/978-3-030-44038-1_102.

14. Xue Yang, Jie Liu, Feng Zhao, \& Vaidya, N. H. (n.d.). A vehicle-to-vehicle communication protocol for cooperative collision warning. The First Annual International Conference on Mobile and Ubiquitous Systems: Networking and Services, 2004. MOBIQUITOUS 2004. doi:10.1109/mobiq.2004.1331717.

15. Zhang, W., Festag, A., Baldessari, R., \& Le, L. (2008). Congestion control for safety messages in VANETs: Concepts and framework. 2008 8th International Conference on ITS Telecommunications. doi:10.1109/itst.2008.4740256.

16. Darus, Mohamad \& Abu Bakar, Kamalrulnizam. (2013). Congestion control algorithm in vanets. World Applied Sciences Journal. 21. 1057-1061. 10.5829/idosi.wasj.2013.21.7.242.

17. Le, Long \& Baldessari, Roberto \& Salvador, Pablo \& Festag, Andreas \& Zhang, Wenhui. (2011). Performance Evaluation of Beacon Congestion Control Algorithms for VANETs. Proceedings of IEEE Global Telecommunications Conference $\quad$ (GLOBECOM). 10.1109/GLOCOM.2011.6133897.

18. Sattari, M. R. J., Noor, R. M., \& Keshavarz, H. (2012). A taxonomy for congestion control algorithms in Vehicular Ad Hoc Networks. 2012 IEEE International Conference on Communication, Networks and Satellite (ComNetSat). doi:10.1109/comnetsat.2012.6380774.

19. Sepulcre, M., Mittag, J., Santi, P., Hartenstein, H., \& Gozalvez, J. (2011). Congestion and Awareness Control in Cooperative Vehicular Systems. Proceedings of the IEEE, 99(7), 1260-1279. doi:10.1109/jproc.2011.2116751.

20. He, J., Chen, H., Chen, T. M., \& Cheng, W. (2010). Adaptive congestion control for DSRC vehicle networks. IEEE Communications Letters, 14(2), 127-129. doi:10.1109/lcomm.2010.02.092002.

21. Yu-Chih Hung, \& Tsung-Chuan Huang. (2014). Data congestion-aware routing for vehicular ad hoc networks in urban environments. 10th International Conference on Wireless Communications, Networking and Mobile Computing (WiCOM 2014). doi:10.1049/ic.2014.0143.

22. Liu, X.-T., Hu, B.-J., Wei, Z.-H., \& Zhu, Z.-X. (2017). A congestion-aware GPCR routing protocol for vehicular ad-hoc network in urban scenarios. 2017 IEEE 9th International Conference on Communication Software and Networks (ICCSN). doi:10.1109/iccsn.2017.8230099. 
23. Xia, Y., Qin, X., Liu, B., \& Zhang, P. (2018). A greedy traffic light and queue aware routing protocol for urban VANETs. China Communications, 15(7), 77-87. https://doi.org/10.1109/cc.2018.8424605

24. Darwish, T., Abu Bakar, K.(2016). Traffic aware routing in vehicular ad hoc networks: characteristics and challenges. Telecommun Syst 61, 489-513. https://doi.org/10.1007/s11235-015-0008-7

25. Abbasi, I. A., Khan, A. S., \& Ali, S. (2018). A Reliable Path Selection and Packet Forwarding Routing Protocol for Vehicular Ad hoc Networks. EURASIP Journal on Wireless Communications and Networking, 2018(1). https://doi.org/10.1186/s13638-018-1233-z

26. Luo, Q., Cai, X., Luan, T. H., \& Ye, Q. (2018). Fuzzy logic-based integrityoriented file transfer for highway vehicular communications. EURASIP Journal on Wireless Communications and Networking, 2018(1). https://doi.org/10.1186/s13638-017-1009-x

27. Veeramani, Vijayakumar \& Joseph K, Suresh. (2018). Fuzzy based clustering for effective congestion control in vanet. International Journal of Pure and Applied Mathematics. 119. 117-127.

28. Liu, X., \& Jaekel, A. (2019). Congestion Control in V2V Safety Communication: Problem, Analysis, Approaches. Electronics, 8(5), 540. doi:10.3390/electronics8050540.

29. Amiri, E., \& Hooshmand, R. (2019). Improved AODV Based on TOPSIS and Fuzzy Algorithms in Vehicular Ad-hoc Networks. Wireless Personal Communications. https://doi.org/10.1007/s11277-019-06894-X

30. Mchergui, A., Moulahi, T. \& Nasri, S. QoS evaluation model based on intelligent fuzzy system for vehicular ad hoc networks. Computing102, 2501-2520 (2020). https://doi.org/10.1007/s00607-020-00820-x.

31. Ahmed, Muhammad \& Iqbal, Saleem \& Awan, Khalid \& Sattar, Kashif \& Khan, Zuhaib Ashfaq \& Sherazi, Husnain. (2019). A Congestion Aware Route Suggestion Protocol for Traffic Management in Internet of Vehicles. Arabian Journal for Science and Engineering. 10.1007/s13369-019-04099-9.

32. Shelke, M., Malhotra, A., \& Mahalle, P. N. (2019). Fuzzy priority based intelligent traffic congestion control and emergency vehicle management using congestion-aware routing algorithm. Journal of Ambient Intelligence and Humanized Computing. https://doi.org/10.1007/s12652-019-01523-8

33. Santamaria, A. F., Fazio, P., Tropea, M., Raimondo, P., \& De Rango, F. (2019). A New Distributed Predictive Congestion aware Re-routing Algorithm for \$lrm CO_2\$ Emissions Reduction. IEEE Transactions on Vehicular Technology, 1-1. https://doi.org/10.1109/tvt.2019.2905753

34. Rahnamaei Yahiabadi, S., Barekatain, B., \& Raahemifar, K. (2019). TIHOO: An Enhanced Hybrid Routing Protocol in Vehicular Ad-hoc Networks. EURASIP Journal on Wireless Communications and Networking, 2019(1). https://doi.org/10.1186/s13638-019-1503-4

35. Miri, S. T., \& Tabatabaei, S. (2020). Improved Routing Vehicular Ad-Hoc Networks (VANETs) Based on Mobility and Bandwidth Available Criteria Using Fuzzy Logic. Wireless Personal Communications. https://doi.org/10.1007/s11277-020-07278-2

36. http://sys.cs.uos.de/bonnmotion/ 
Figures

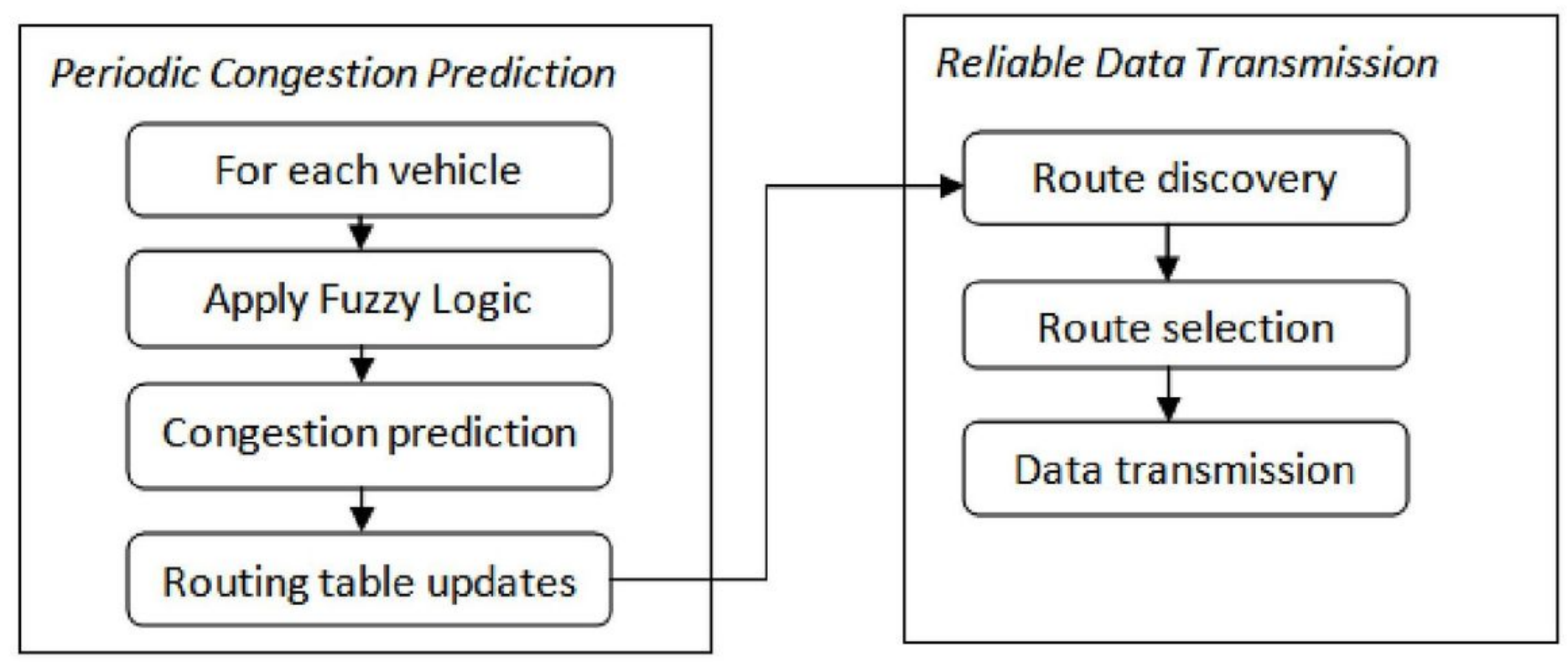

Figure 1

Architecture of ACARP protocol 


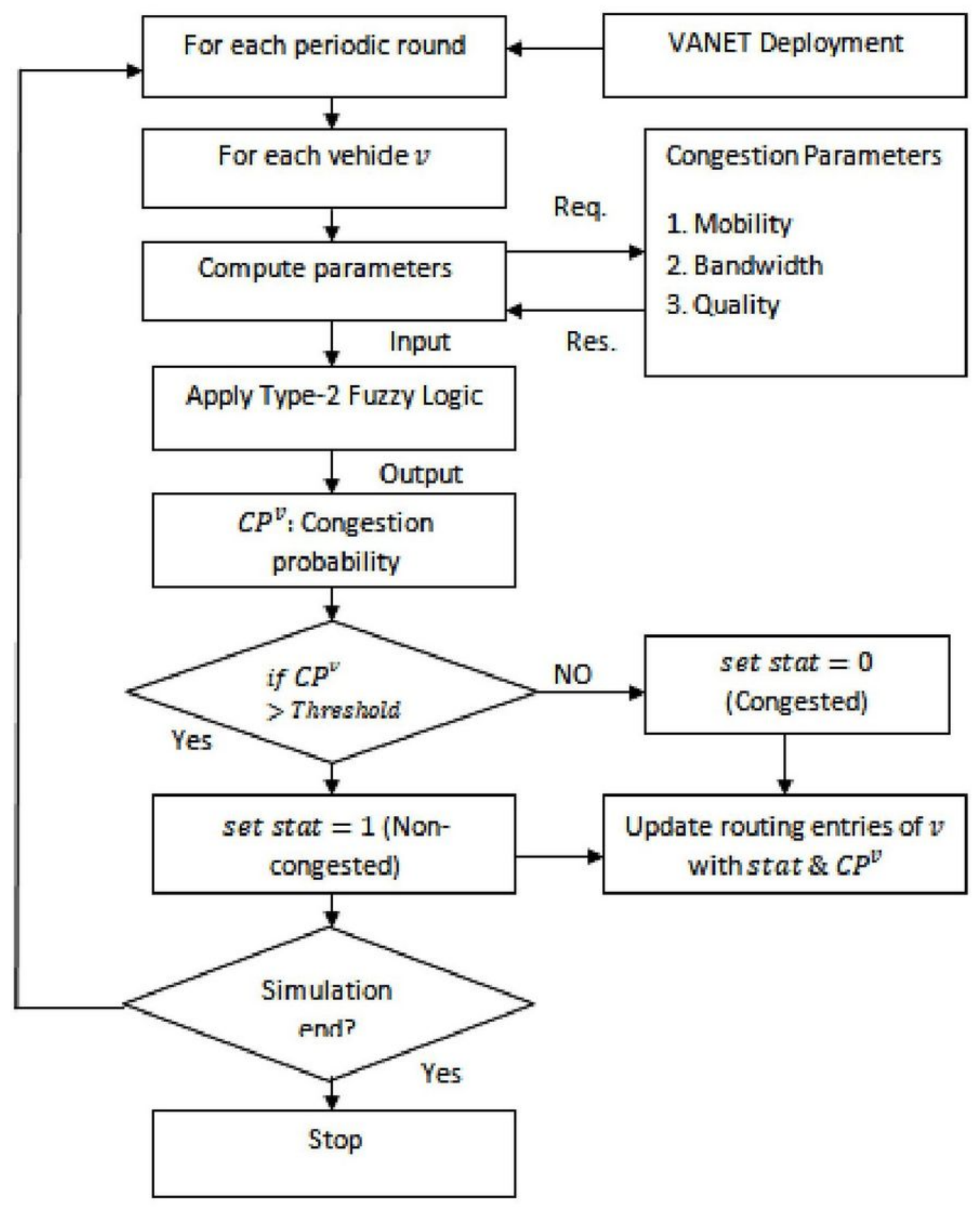

Figure 2

Adaptive congestion prediction using type-2 fuzzy logic approach 


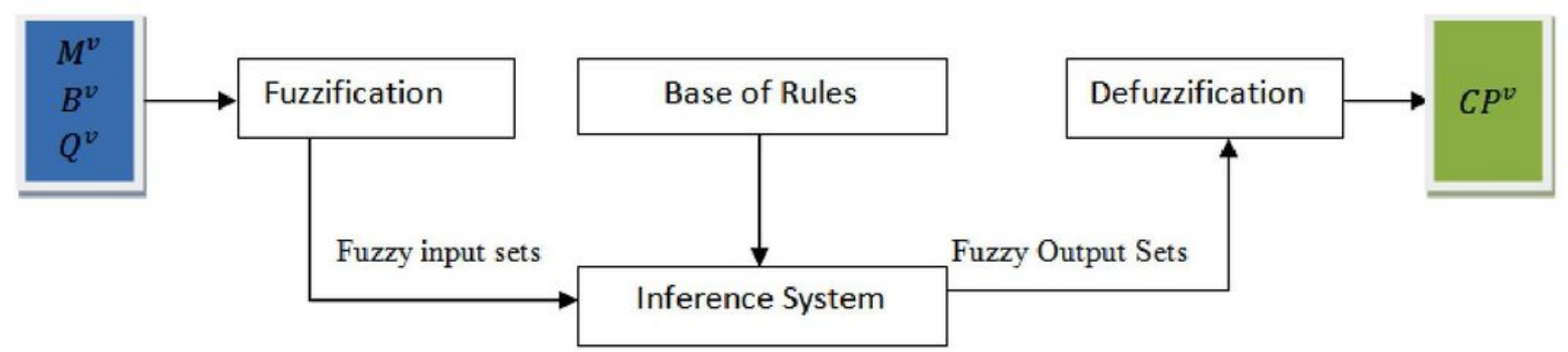

Figure 3

Proposed model of type-2 fuzzy Mamdani fuzzy logic method

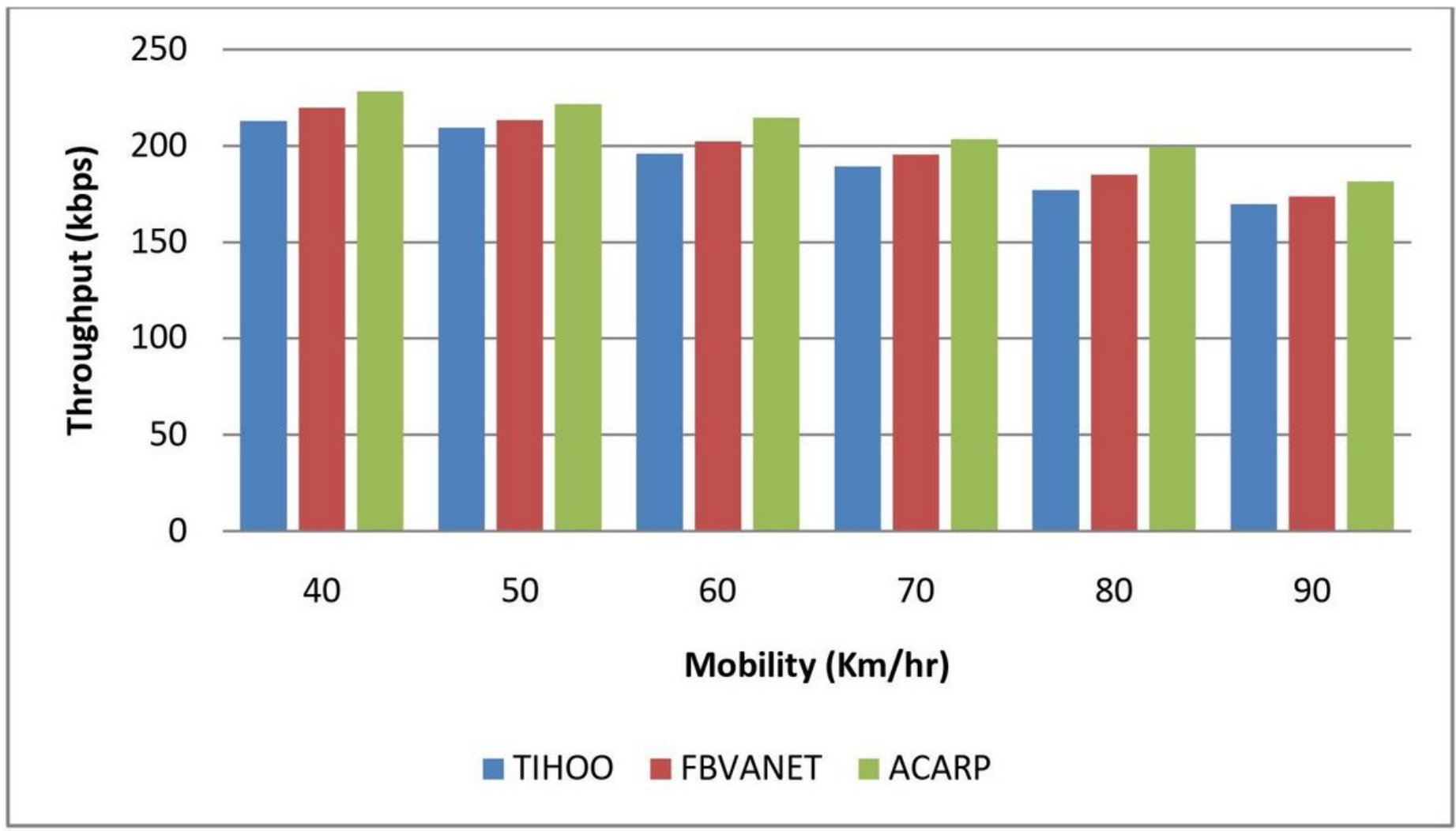

Figure 4

Throughput performance evaluations in mobility scenario 


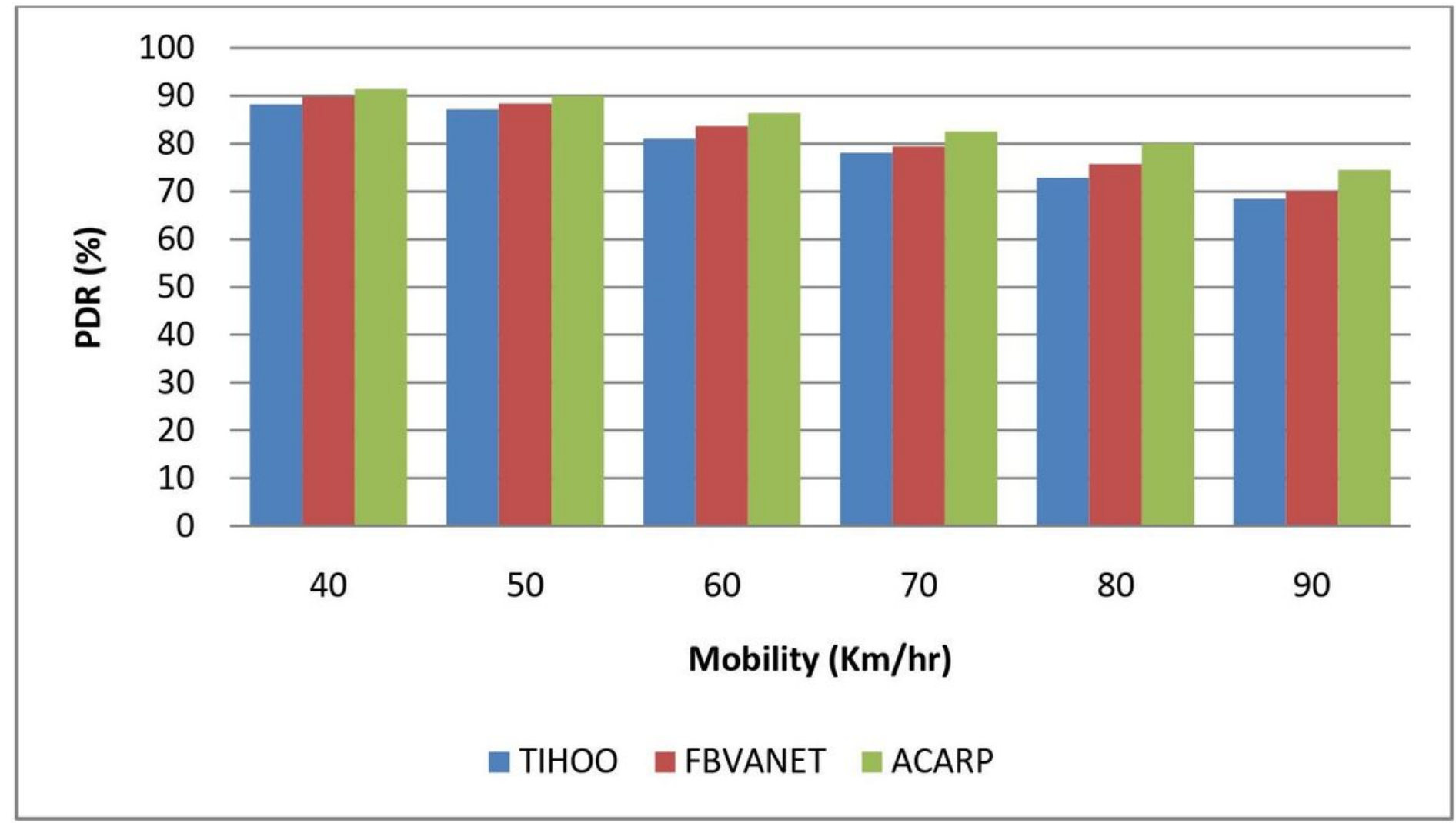

Figure 5

PDR performance evaluations in mobility scenario

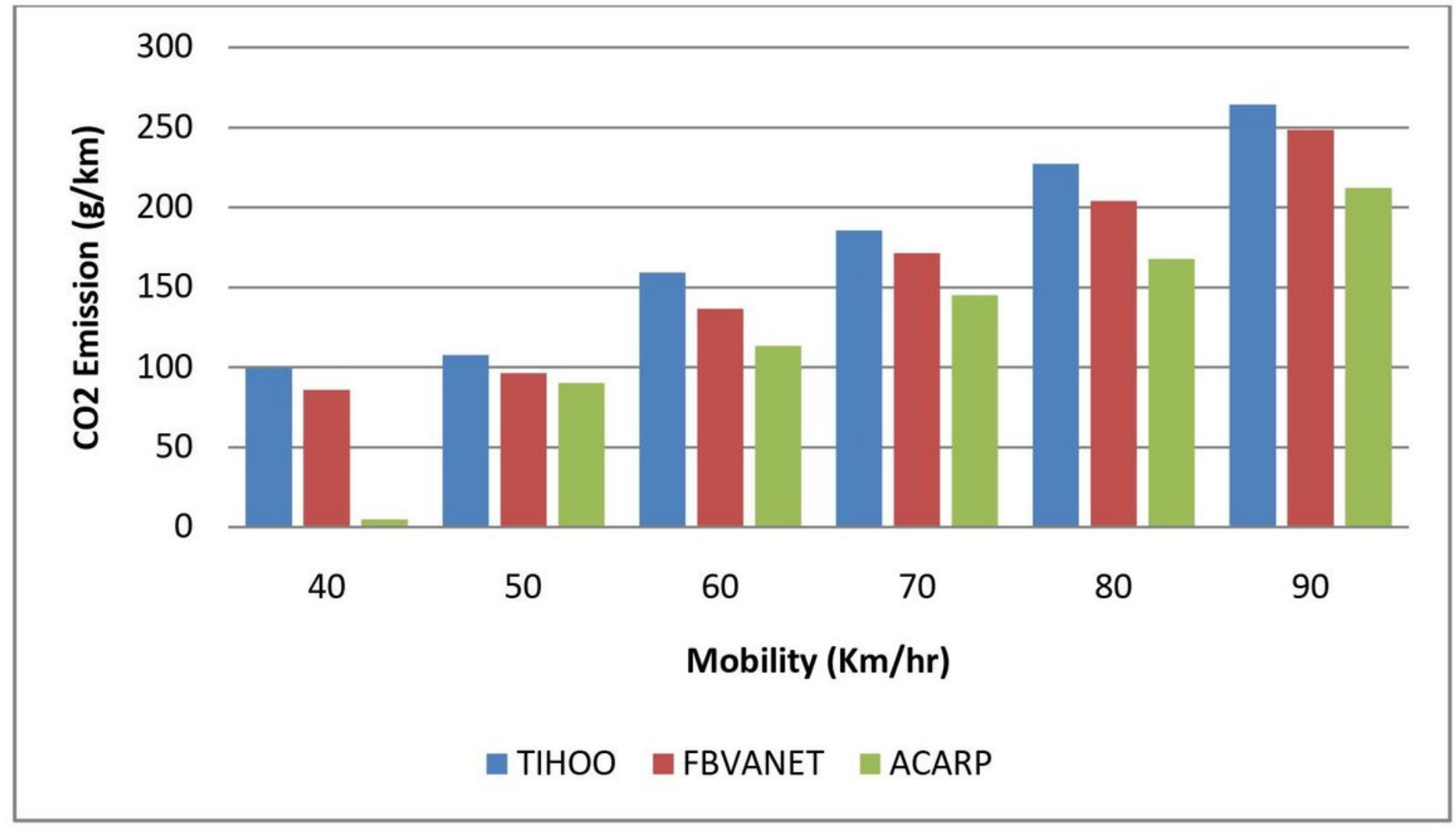


Figure 6

CO2 emission performance evaluations in mobility scenario

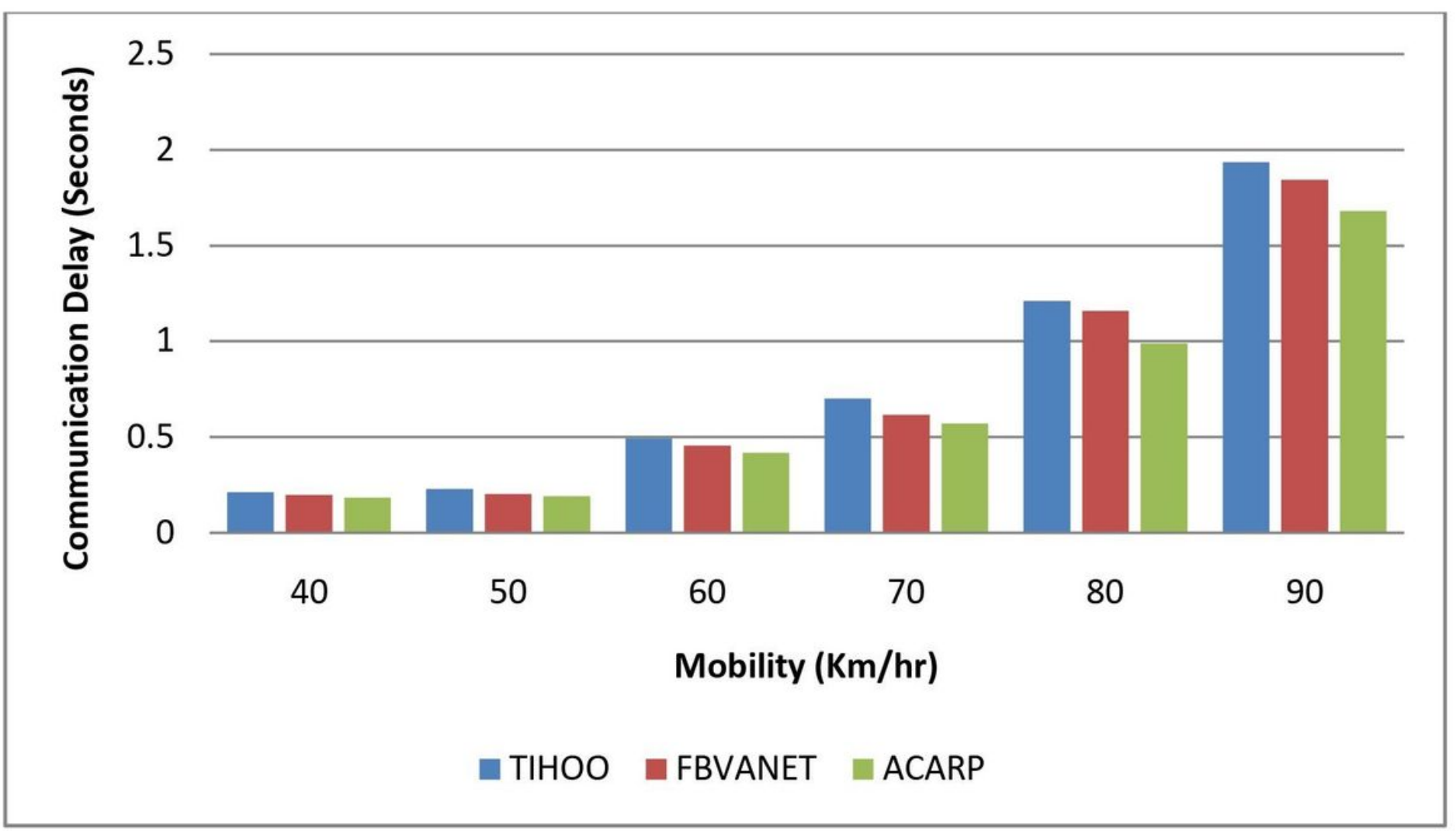

Figure 7

Communication delay performance evaluations in mobility scenario 


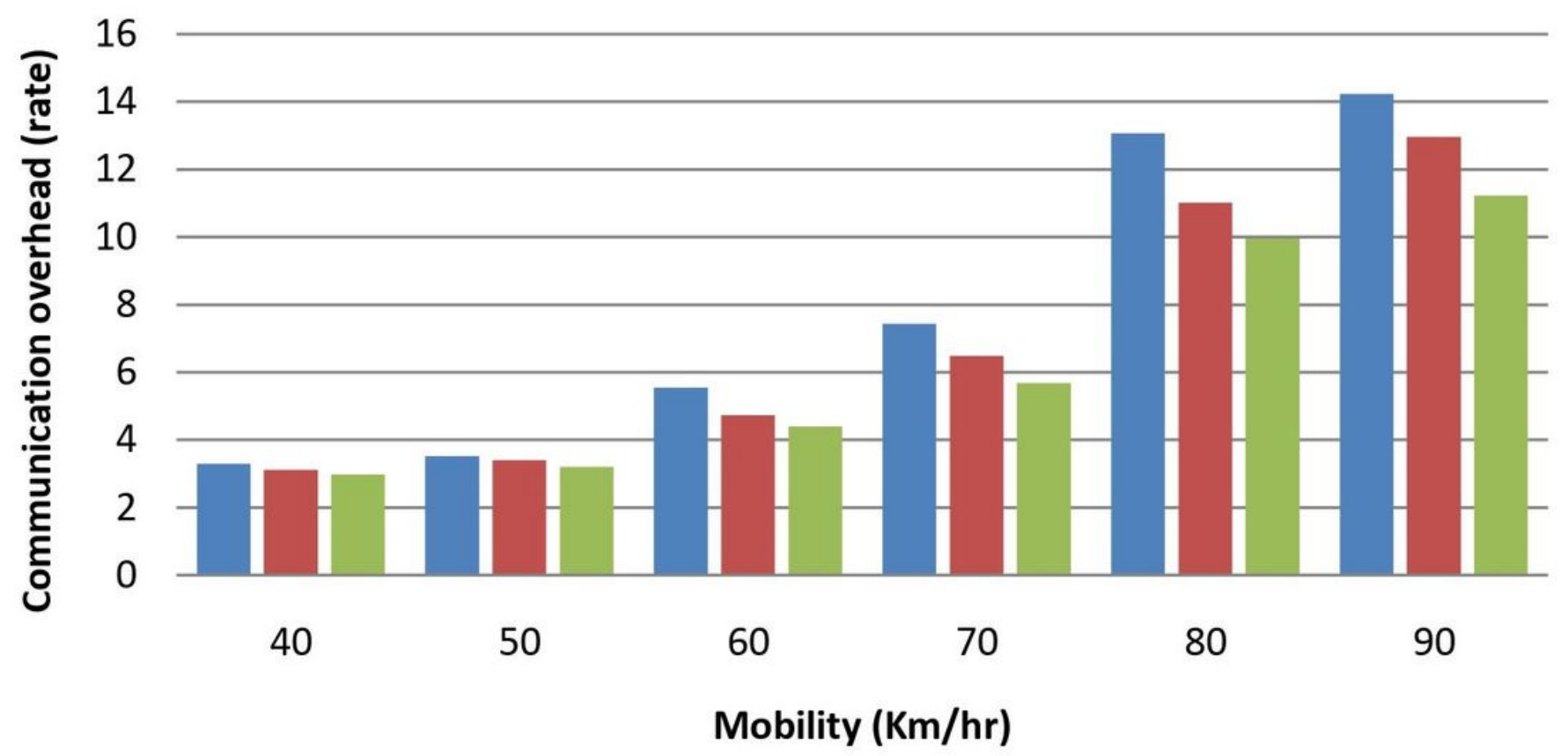

$\square$ TIHOO $\square$ FBVANET $\square$ ACARP

Figure 8

Communication overhead performance evaluations in mobility scenario

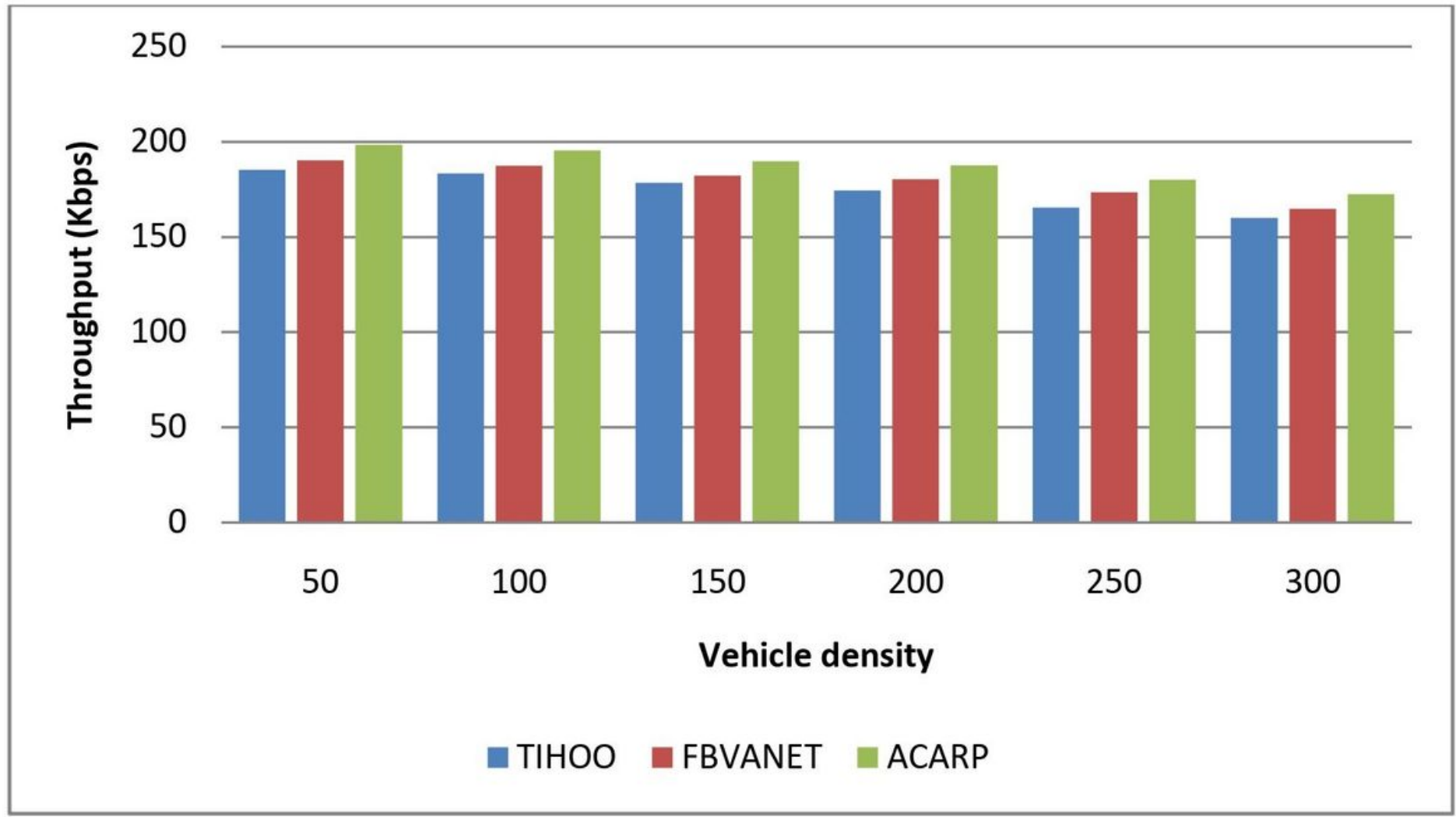

Figure 9 
Throughput performance evaluations in density scenario

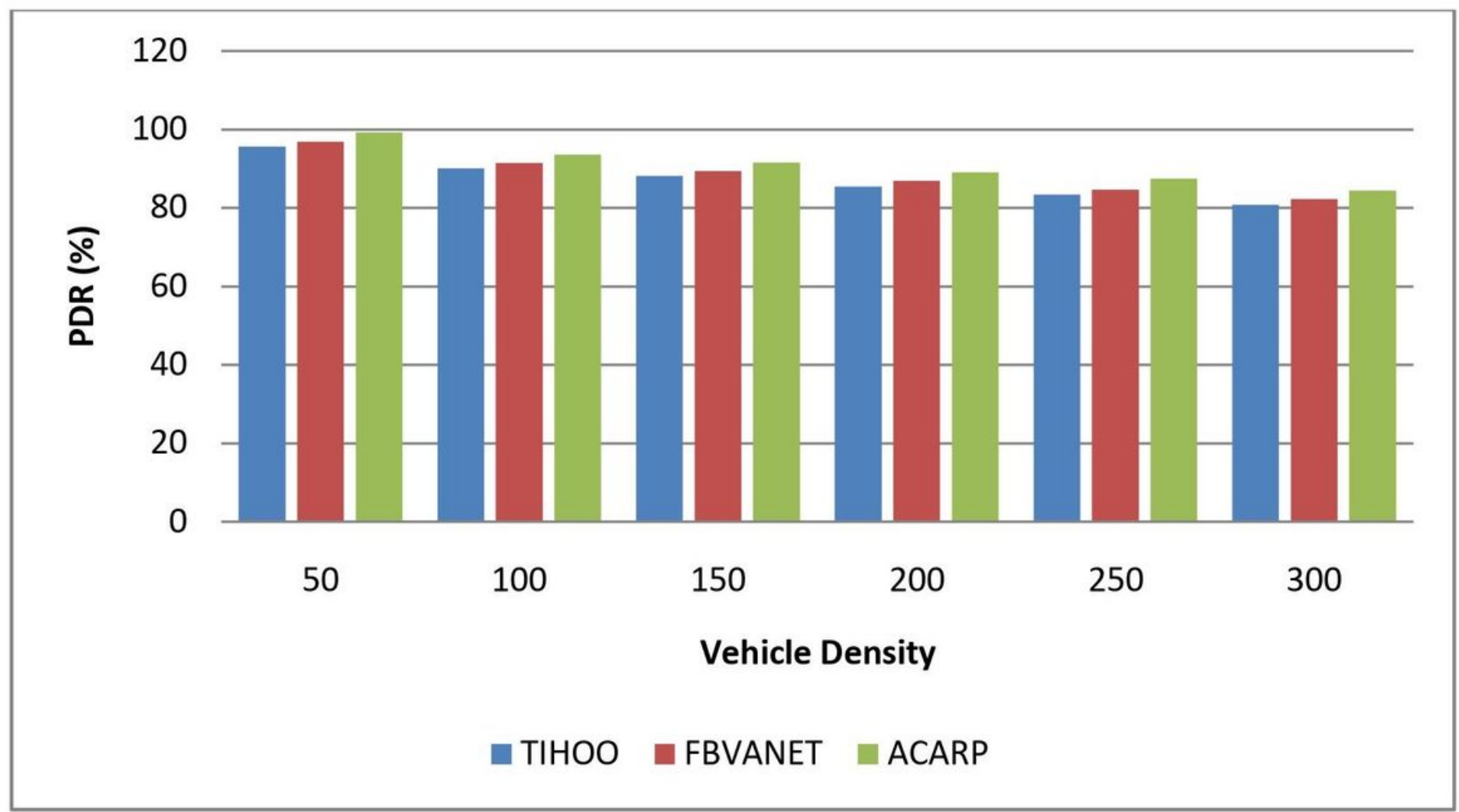

Figure 10

PDR performance evaluations in density scenario

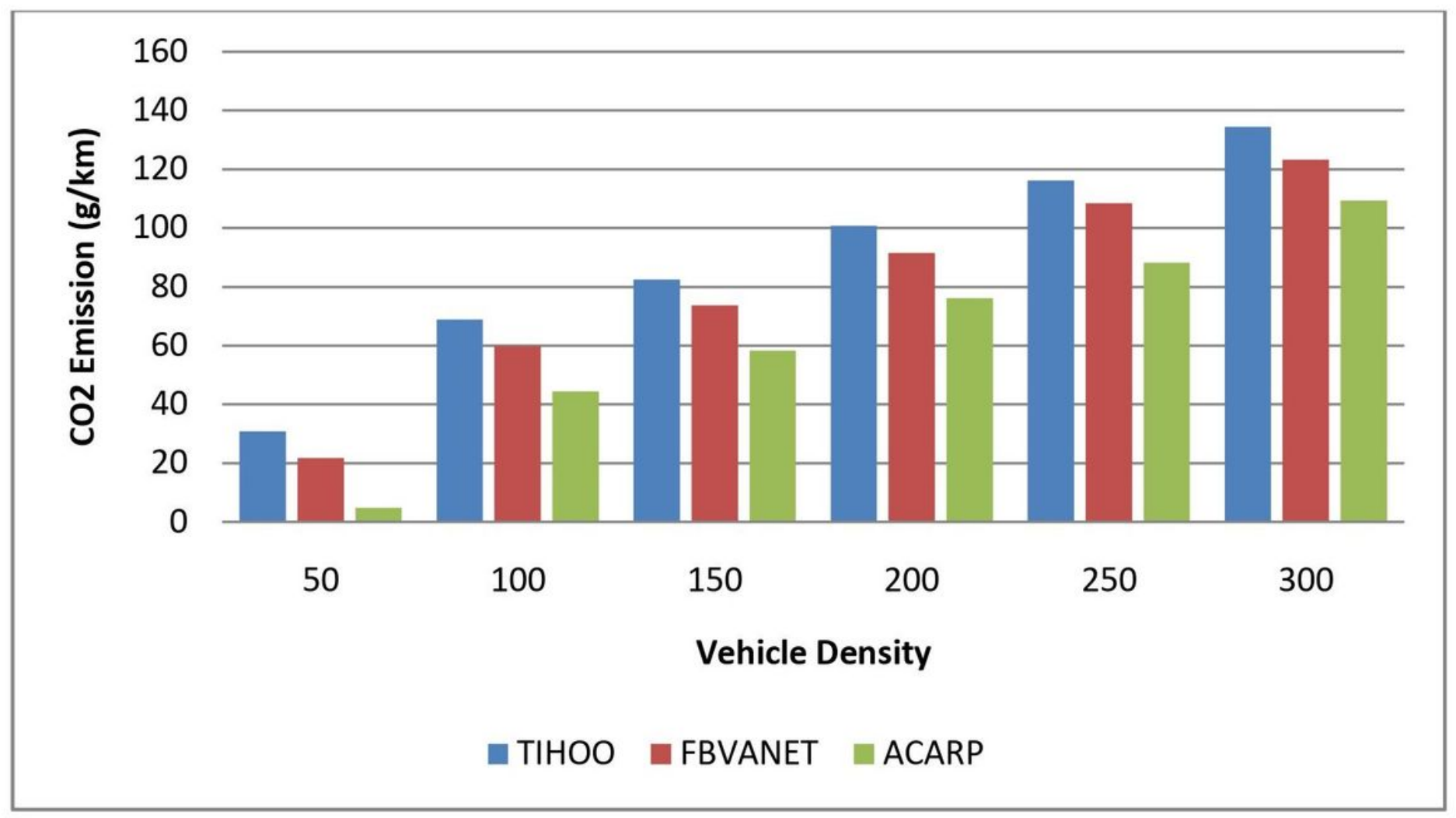


Figure 11

CO2 emission performance evaluations in density scenario

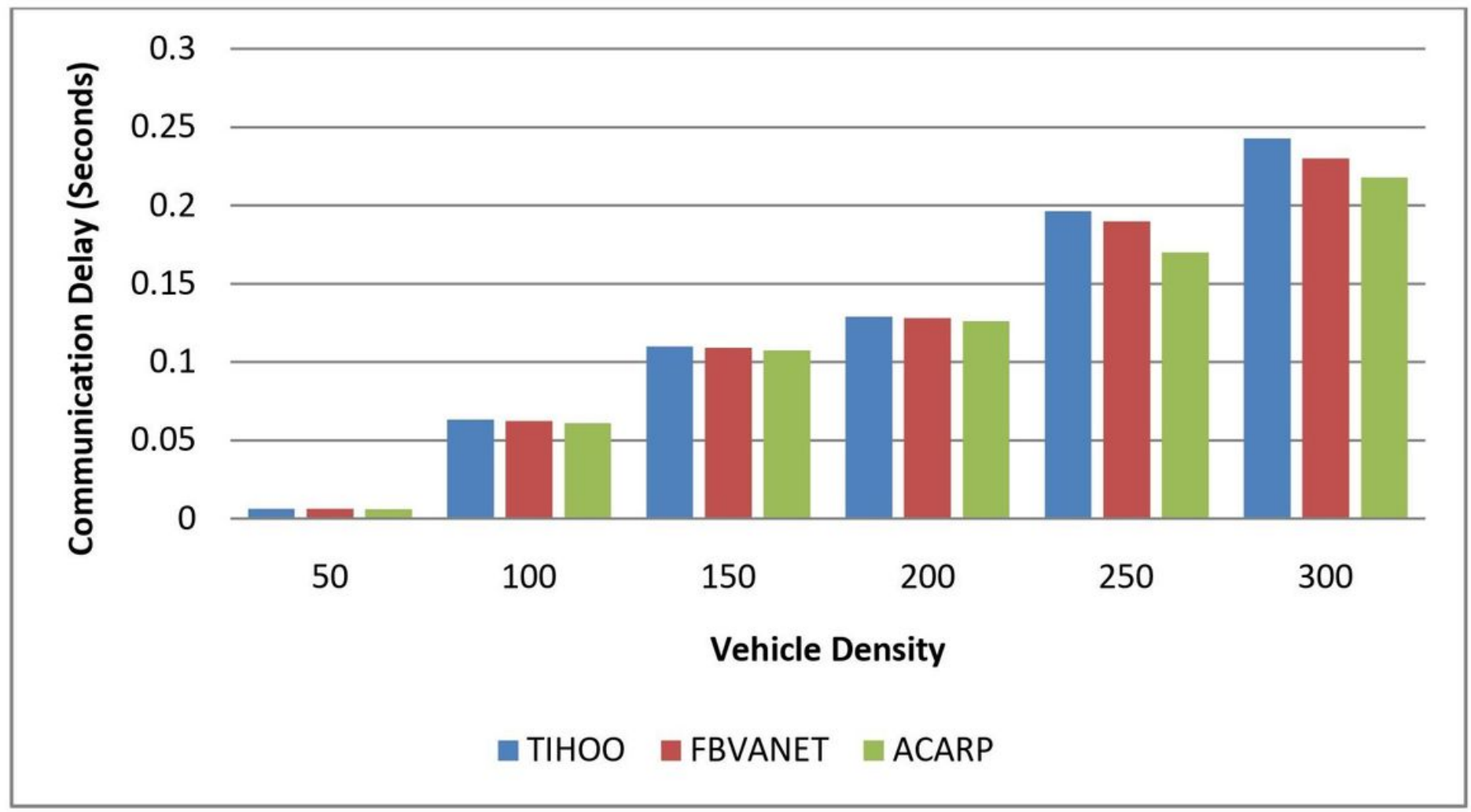

Figure 12

Communication delay performance evaluations in density scenario 


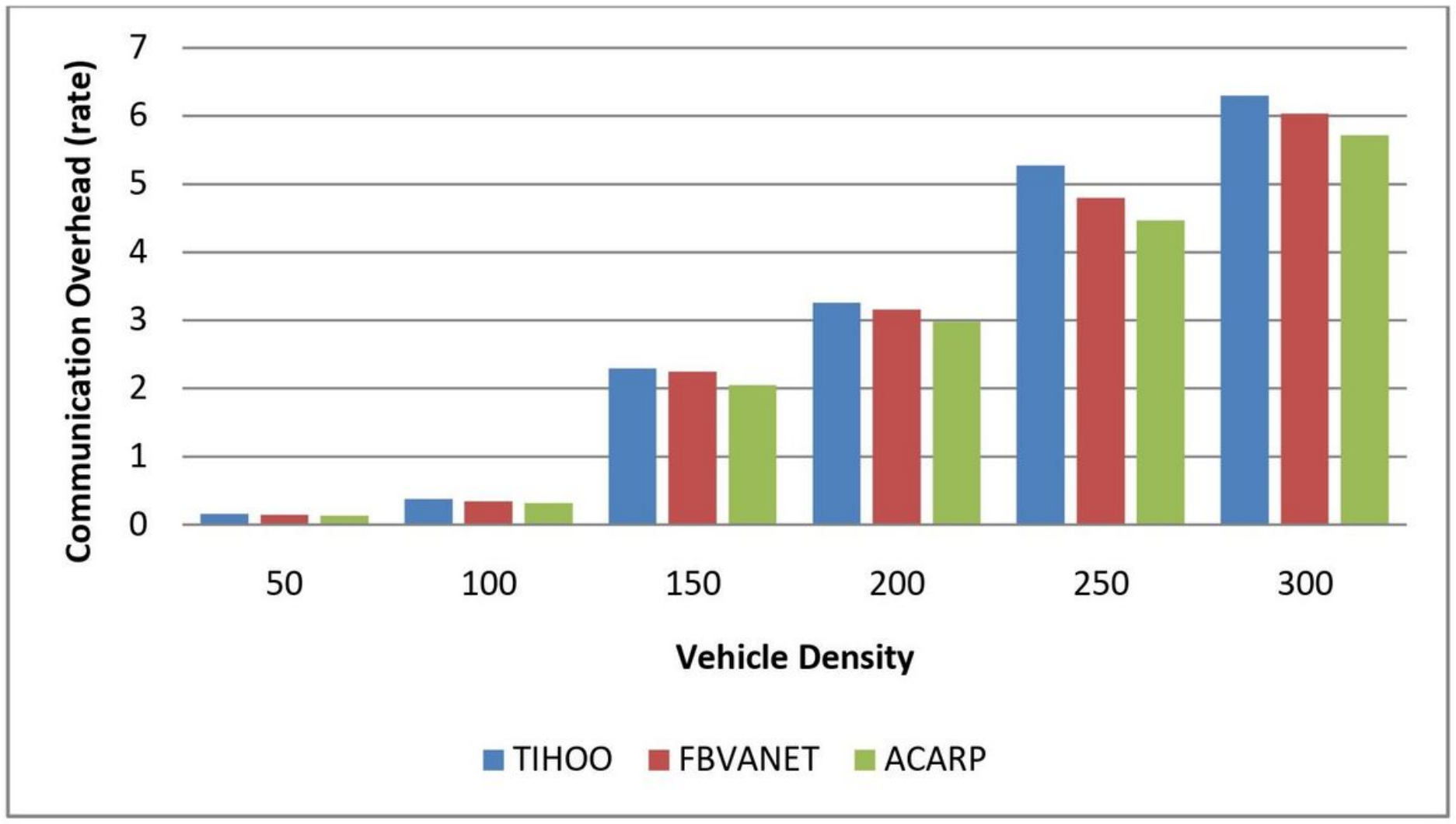

Figure 13

Communication overhead performance evaluations in density scenario 